\title{
Simulated decadal oscillations of the Atlantic meridional overturning circulation in a cold climate state
}

\author{
Masakazu Yoshimori · Christoph C. Raible • \\ Thomas F. Stocker · Manuel Renold
}

Received: 10 July 2008/Accepted: 9 February 2009/Published online: 28 February 2009

(C) Springer-Verlag 2009

\begin{abstract}
The significance of the Atlantic meridional overturning circulation (MOC) for regional and hemispheric climate change requires a complete understanding using fully coupled climate models. Here we present a persistent, decadal oscillation in a coupled atmosphereocean general circulation model. While the present study is limited by the lack of comparisons with paleo-proxy records, the purpose is to reveal a new theoretically interesting solution found in the fully-coupled climate model. The model exhibits two multi-century-long stable states with one dominated by decadal MOC oscillations. The oscillations involve an interaction between anomalous advective transport of salt and surface density in the North Atlantic subpolar gyre. Their time scale is fundamentally determined by the advection. In addition, there is a link between the MOC oscillations and North Atlantic Oscillation (NAO)-like sea level pressure anomalies. The analysis suggests an interaction between the NAO and an anomalous subpolar gyre circulation in which sea ice near and south of the Labrador Sea plays an important role in generating a large local thermal anomaly and a meridional temperature gradient. The latter induces a positive feedback via synoptic eddy activity in the atmosphere. In
\end{abstract}

M. Yoshimori - C. C. Raible - T. F. Stocker - M. Renold

Climate and Environmental Physics, Physics Institute,

University of Bern, Bern, Switzerland

M. Yoshimori ( $\square)$

Center for Climate System Research, University of Tokyo,

5-1-5, Kashiwanoha, Kashiwa, Chiba 277-8568, Japan

e-mail: masakazu@ccsr.u-tokyo.ac.jp

C. C. Raible - T. F. Stocker

Oeschger Centre for Climate Change Research,

University of Bern, Bern, Switzerland addition, the oscillation only appears when the Nordic Sea is completely covered by sea ice in winter, and deep convection is active only near the Irminger Sea. Such conditions are provided by a substantially colder North Atlantic climate than today.

Keywords Thermohaline circulation .

Meridional overturning circulation - Decadal variability ·

North Atlantic Oscillation

\section{Introduction}

The Atlantic meridional overturning circulation (MOC) has been the subject of many studies which focused on its role for past (Stocker 2000), as well as for future climate change (IPCC 2007). It is proposed that the Atlantic MOC induces basin-wide sea surface temperature (SST) variations, known as Atlantic multidecadal oscillations (AMO, Hurrell et al. 2006 and references therein). In addition, an increasing number of paleo-proxy records and modelling studies suggest that changes in this current system are responsible for past abrupt climate variations such as the Younger Dryas and Dansgaard-Oeschger events (Broecker 1998; Stocker 1998; Blunier et al. 1998; Blunier and Brook 2001; Stocker and Johnsen 2003; Knutti et al. 2004). Models have shown that the climatic impact of the collapse of the Atlantic MOC is significant in the absence of any counteracting forcings (Manabe and Stouffer 1988; Vellinga and Wood 2002; Zhang and Delworth 2005; Stouffer et al. 2006).

Early modelling studies of Atlantic MOC variations used ocean-only models typically with the so-called mixed boundary conditions (Table 1). It became clear that the MOC oscillations are sensitive to the treatment of the upper 
Table 1 Some previous modelling studies on decadal to a century scale MOC variations

\begin{tabular}{|c|c|c|c|c|}
\hline \# & Model type & Period & Region of activity & Mechanism \\
\hline 1 & $\begin{array}{l}\text { OGCM with mixed boundary } \\
\text { conditions }(\mathrm{bc})\end{array}$ & $\begin{array}{l}\text { Decadal to } \\
\text { interdecadal }\end{array}$ & Subpolar & $\begin{array}{l}\text { Self-sustained oscillation (interaction with } \\
\text { advective speed) }\end{array}$ \\
\hline 2 & $\begin{array}{l}\text { Box and intermediate models, } \\
\text { and OGCM with mixed bc }\end{array}$ & $\begin{array}{l}\text { Decadal to } \\
\text { interdecadal }\end{array}$ & Subpolar & $\begin{array}{l}\text { Self-sustained oscillation (interaction with ice } \\
\text { melting) }\end{array}$ \\
\hline 3 & AOGCM with flux adj. & 50 years & Subtropics, subpolar & Stochastically-excited damped oceanic mode \\
\hline 4 & $\begin{array}{l}\text { Intermediate ocean model with } \\
\text { mixed bc }\end{array}$ & $10-40$ years & $\begin{array}{l}\text { Labrador Sea and northern North } \\
\text { Atlantic }\end{array}$ & Integration of white noise \\
\hline 5 & $\begin{array}{l}\text { Intermediate ocean and ice model } \\
\text { with mixed bc }\end{array}$ & $17-30$ years & Subpolar & $\begin{array}{l}\text { Interaction with thermal insulating effect of } \\
\text { ice }\end{array}$ \\
\hline 6 & Box model with mixed bc & $\begin{array}{l}\text { Decades to } \\
\text { centuries }\end{array}$ & - & Integration of white noise \\
\hline 7 & $\begin{array}{l}\text { Intermediate ocean model with } \\
\text { const. heat flux }\end{array}$ & 50 years & Subtropics, subpolar & $\begin{array}{l}\text { Self-sustained oscillation (interaction with } \\
\text { heat transport) }\end{array}$ \\
\hline 8 & Box model with mixed bc & 51 years & - & Stochastically-excited damped oceanic mode \\
\hline 9 & AOGCM with flux adj. & 35 years & Subtropics, subpolar & Coupled atmosphere-ocean mode \\
\hline 10 & $\begin{array}{l}\text { Intermediate ocean model with } \\
\text { EBM }\end{array}$ & $\begin{array}{l}\text { Decades to } \\
\text { centuries }\end{array}$ & Atlantic & Stochastically-excited oscillations \\
\hline 11 & OGCM with EBM & 20 years & Subpolar, Arctic & $\begin{array}{l}\text { Stochastically-excited damped oceanic mode } \\
\text { by ice export and melting }\end{array}$ \\
\hline 12 & AOGCM w/o flux adj. & 100 years & Tropics, subtropics, subpolar & Interaction with cross-equatorial SST gradient \\
\hline 13 & AOGCM w/o flux adj. & 24 years & Subpolar & Interaction with subpolar gyre \\
\hline 14 & AOGCM w/o flux adj. & 25 years & Subpolar & Interaction with subpolar gyre \\
\hline 15 & AOGCM w/o flux adj. & 70 years & Subtropics, subpolar, Arctic & Stochastically-excited damped oceanic mode \\
\hline 16 & AOGCM w/o flux adj. & 20 years & Subpolar & Interaction with subpolar gyre \\
\hline
\end{tabular}

1, Weaver and Sarachik (1991a, b); Weaver et al. (1991, 1993); Weaver and Hughes (1994); 2, Yang and Neelin (1993, 1997); 3, Delworth et al. (1993); 4, Weisse et al. (1994); 5, Zhang et al. (1995); 6, Bryan and Hansen (1995); 7, Greatbatch and Zhang (1995); 8, Griffies and Tziperman (1995); 9, Timmermann et al. (1998); 10, Aeberhardt et al. (2000); 11, Holland et al. (2001); 12, Vellinga and Wu (2004); 13, Dai et al. (2005); 14, Dong and Sutton (2005); 15, Jungclaus et al. (2005), and 16, Danabasoglu (2008)

boundary conditions for ocean models and the presence of stochastic atmospheric forcing (Zhang et al. 1993; Mikolajewicz and Maier-Reimer 1994; Rahmstorf and Willebrand 1995; Tziperman et al. 1994; Rahmstorf 1996; Toggweiler et al. 1996). Therefore, it is desirable to investigate the behavior of MOC oscillations with a model which explicitly simulates the full interactions between atmosphere and ocean including wind stress feedbacks.

Using an atmosphere-ocean general circulation model (GCM), Delworth et al. (1993) found multidecadal Atlantic MOC oscillations. The simulated oscillation is a result of the interaction between MOC and anomalous gyre circulation. The reduced MOC produces cold and dense anomalies in the middle of the North Atlantic, which induces an anomalous anticyclonic gyre circulation. This anomalous gyre circulation, in turn, enhances salinity and density anomalies in the sinking region which enhances the MOC. These processes comprise one half of a MOC cycle. The oscillation is described as a stochastically-excited damped oceanic oscillator (Delworth and Greatbatch 2000), and similar oscillations are reproduced in the higher resolution version of the model (Delworth et al. 2002).
Essentially the same mechanism is responsible for interdecadal MOC variations simulated with different models (Dong and Sutton 2005; Dai et al. 2005). Building on this mechanism, Jungclaus et al. (2005) found an interaction between the MOC, the gyre circulation in the Nordic Seas, and freshwater exchanges between subpolar North Atlantic, Nordic Seas, and Arctic Ocean. In their multidecadal oscillations, the accumulation and subsequent export of positive salinity anomalies in and from the Arctic Ocean plays an important role.

On the other hand, the multidecadal MOC oscillations found by Timmermann et al. (1998) were described as a coupled atmosphere-ocean mode in which a link between SST anomaly and the North Atlantic Oscillation (NAO) plays a key role. The negative SST anomaly accompanies the negative NAO phase, which increases the surface salinity via anomalous evaporation and Ekman transport. Accumulation of salinity and density anomalies lead to an increase in the deep convection. With some delays, it results in the intensification of the MOC and heat transport, which produces the positive SST anomaly, completing a half oscillation cycle. The importance of a "weak" air-sea 
coupling involving the NAO was suggested by Dong and Sutton (2005) whereas Dai et al. (2005) argues the presence of a "strong" coupling in their interdecadal variations.

Furthermore, the tropical Atlantic plays a key role in the centennial variability found by Vellinga and $\mathrm{Wu}$ (2004). The MOC generates a cross-equatorial SST gradient which induces the meridional displacement of the intertropical convergence zone. This in turn produces a salinity anomaly via changes in precipitation, which is transported to the convection region. The relatively long time scale is explained by the transport processes involving recirculation and diapycnal transfer rather than surface boundary currents.

The above and other modelling studies capture aspects of observed Atlantic variations. Nevertheless, the time scale of the MOC oscillations and the detailed mechanisms vary significantly between the models shown in Table 1 . In addition, sparse observations in the deep ocean limit the current understanding of the MOC variability (Cunningham et al. 2007). Therefore, it is useful to investigate the behavior of MOC variations in a wide range of parameter space including past and future climate states. In this study, we investigate simulated decadal MOC oscillations in a substantially colder climate than today but not as cold as the last glacial maximum (LGM).

In the next section, we briefly describe the model, and the experiments are described in Sect. 3. The results are presented in Sect. 4, followed by discussion and conclusions in Sect. 5.

\section{Model description}

The model used in this study is CCSM 3 developed by NCAR (Collins et al. 2006a). The model consists of atmosphere, ocean, land surface, and sea ice components coupled without flux adjustments. We choose the lowest resolution setting of the three model versions released by NCAR (Yeager et al. 2006; Danabasoglu 2008).

The atmospheric component is based on the primitive equations with a triangular spectral truncation at wave number 31, having 96 longitudinal and 48 latitudinal grid points (Collins et al. 2006b). In the vertical, there are 26 hybrid sigma-pressure levels between the terrain-following surface and $2.2 \mathrm{hPa}$. Details of the land surface component are described in Oleson et al. (2004).

The ocean component is formulated based on the ocean primitive equations. The finite-difference method is employed for horizontal and vertical discretizations. There are 25 unevenly spaced depth levels, and it has a nominal horizontal resolution of $3^{\circ}$, which is refined to $0.9^{\circ}$ near the equator. Two numerical poles are located in Greenland and Antarctica. Hence, the horizontal resolution is refined near
Greenland as small as a few tens of kilometers. The vertical mixing, including deep convection, is represented by the so-called KPP scheme (Large et al. 1994). For tracers, the Gent-McWilliams isopycnal mixing parameterization (Gent and McWilliams 1990) is applied. In addition, the anisotropic viscosity parameterization is used.

The sea ice component has the same horizontal resolution as the ocean component and is based on thermodynamic and dynamic equations. The thermodynamic equation is solved for four layers of ice and a single snow layer in the vertical dimension. Horizontal momentum equations are solved in which the internal ice stress is derived from an elastic-viscous-plastic rheology. The subgrid scale ice thickness distribution is parameterized, using five thickness categories.

A series of studies using CCSM3 were published in a special issue on the Community Climate System Model in Journal of Climate (vol 19, issue 11, June 2006). The simulated present-day condition for the lowest resolution version of the model is comprehensively described in Yeager et al. (2006). Further information including a detailed description of the model are also available at the CCSM web page (http://www.ccsm.ucar.edu/).

\section{Experiments}

While the long-term goal of our experiments is to simulate and study climate variability and change over the period 1500-1990 A.D., the simulations produced interesting dynamics which appear of a more general nature. An overview of all experiments addressed in this study is listed in Table 2; the sequence of the experiments is illustrated in Fig. 1. The stable present-day control simulation was produced for 179 years and named CTRL. The restart files of the control simulation, after 800 years of spinup in stabilizing the model climate state to the present-day (1990 A.D.) forcing, were kindly provided by NCAR. The specified external forcing includes 1990 A.D. values of total solar irradiance, well-mixed greenhouse gases, ozone, and aerosols (sulfate, carbonaceous, sea salt, and mineral dust)-Otto-Bliesner et al. (2006). For the transient simulations of the last 500 years, two different sets of initial conditions were considered. The first set of initial conditions was obtained from an equilibrium simulation under a perpetual 1500 A.D. forcing. Starting from the CTRL simulation and applying the 1500 A.D. forcing, 561 years were integrated as a spinup. A total of 375 years in the middle of the spinup were integrated with the acceleration technique of Bryan (1984). The stable part of this simulation, i.e., post-spinup period, is named EQ1500. Two simulations, TR1 and TR2 are started from different years of EQ1500, 10 years apart from each other. Another transient 
Table 2 The list of experiments

\begin{tabular}{llr}
\hline Experiment & Description & Length (years) \\
\hline CTRL & 1990 A.D. equilibrium simulation after spinup & 179 \\
EQ1500 & 1500 A.D. equilibrium simulation after spinup & 101 \\
TR1 & Transient experiment with a time-varying forcing for 1501-1990 A.D., starting from a year in EQ1500 & 490 \\
TR2 & Same forcing as TR1 but with slightly different initial conditions: starting 10 years after TR1 in EQ1500 & 490 \\
TR3 & Same forcing as TR1 but with very different initial conditions: starting during the spinup phase of EQ1500 & 490 \\
ST1 & Same forcing as EQ1500 but starting from 1710 A.D. in TR1 & 206 \\
\hline
\end{tabular}

Length represents years used for the analysis, and not entire period of integrations

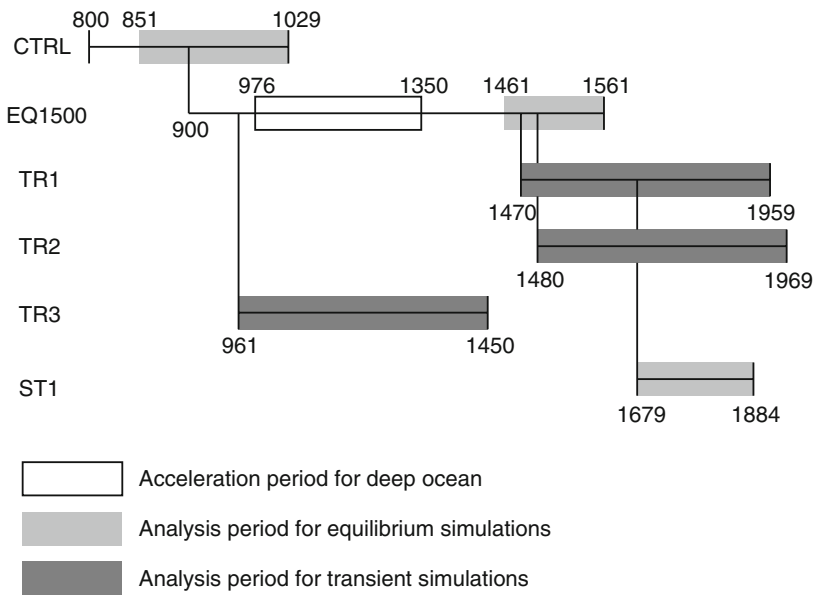

Fig. 1 Experimental procedures: numbers represent cumulative model integration years starting from the present-day control simulation. A model spinup of 800 years for the present-day condition was performed by NCAR. See text for details

simulation, named TR3, used the second set of initial conditions which was taken from the perpetual 1500 A.D. simulation but during the non-accelerated spinup phase. In all three transient simulations (TR1, TR2, and TR3), timevarying external forcing due to solar variability, volcanic eruptions, and well-mixed greenhouse gases were applied (Fig. 2). The greenhouse gas forcing consists of $\mathrm{CO}_{2}, \mathrm{CH}_{4}$, and $\mathrm{N}_{2} \mathrm{O}$ and is based on data of Etheridge et al. (1996), Blunier et al. (1995), and Flückiger et al. (1999, 2002), respectively. The solar forcing is represented by changing the total solar irradiance $S$. The net radiative forcing $L_{\text {net }}$ of Crowley (2000) was scaled to data provided by Lean et al. (1995) for the overlapping period of 1610-1990:

$S=1365.06 \mathrm{~W} \mathrm{~m}^{-2}+5.40 L_{\mathrm{net}}$

The volcanic forcing estimates of Crowley (2000) were first converted to total aerosol masses using the relation obtained from the six strongest volcanic eruptions in the last 130 years (Ammann et al. 2003). These total aerosol masses were then distributed in the lower stratosphere. As Crowley (2000) provides major tropical eruptions, which are thought to be climatically important, we weighted the
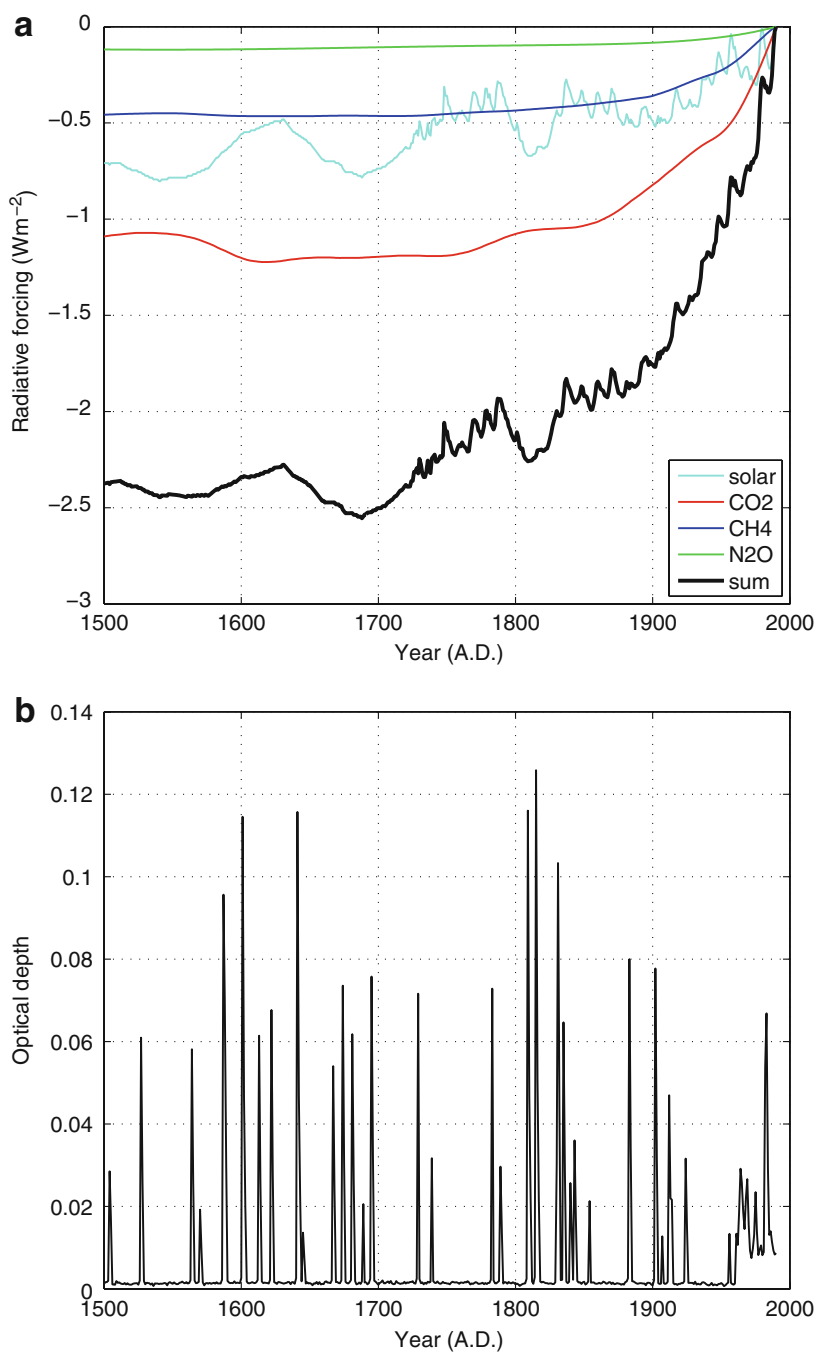

Fig. 2 Forcing from 1500 to 1990 A.D. a Solar, $\mathrm{CO}_{2}, \mathrm{CH}_{4}$, and $\mathrm{N}_{2} \mathrm{O}$ forcing. The forcing is represented after conversion to the equivalent radiative forcing assuming the planetary albedo of 0.3 and using the simplified formula given in IPCC (2001, Table 6.2). Forcings are referenced to 1990 A.D.; and b optical depth in visible band representing the volcanic forcing

aerosol masses by a latitudinal cosine function conserving the total mass so that more aerosols are distributed in lower latitudes. Note that volcanic aerosols are added throughout 
the entire year of eruptions ignoring the often unknown exact dates of eruptions. The uncertainty of the solar and the volcanic forcing is rather high (Rind et al. 2004; Yoshimori et al. 2005, 2006). Although the implementation of volcanic aerosols in the model is crude, the details do not affect the main conclusion, because the oscillation investigated is not externally driven.

The additional experiment, named ST1, was integrated using 1710 A.D. of the TR1 simulation as initial condition and the perpetual 1500 A.D. forcing as boundary conditions. This experiment is aimed at separating the effect of timevarying external forcing from internal model variability by comparing the TR1 or TR2 and ST1 experiments, and also at investigating the stability of the oscillatory mode. We do not expect a large difference in results if the integration were continued on under the fixed 1710 A.D. forcing, rather than switching back to 1500 A.D. forcing, because the forcing difference in these two periods is small (estimated as $0.09 \mathrm{~W} \mathrm{~m}^{-2}$ in radiative forcing). The ST1 experiment serves as a core experiment in this study because the decadal MOC oscillations found are attributed to unforced internal variability.

\section{Results}

\subsection{Characteristics of the MOC oscillation}

Figure $3 \mathrm{a}$ shows time series of the maximum value of the annual mean meridional overturning stream function below $500 \mathrm{~m}$ and north of $28^{\circ} \mathrm{N}$ in the North Atlantic (MOC index hereafter) in all experiments. The CTRL experiment exhibits a stable MOC with a realistic strength of about 16.4 Sv on average (Ganachaud and Wunsch 2000; Ganachaud 2003; Lumpkin and Speer 2003; Smethie Jr. and Fine 2001; Talley et al. 2003). The EQ1500 experiment exhibits a similar but slightly weaker MOC of about 14.9 Sv. In contrast, the TR1 and TR2 simulations show a substantial weakening of the MOC beginning at the midsixteenth century, settling down at the late seventeenth century, and remaining in that weak state thereafter ( $\sim 10.6 \mathrm{~Sv}$ between 1701 and 1990 in both experiments). These reduced MOCs, of course, are inconsistent with modern-day estimates cited above. On the other hand, the TR3 simulation starting from a very different initial condition from the TR1 and TR2 simulations shows a relatively stable MOC time series over the last 500 years with an average strength of about $16.9 \mathrm{~Sv}$ between 1701 and 1990. It appears that the TR3 simulation is much more realistic than the TR1 and TR2 simulations in terms of the MOC strength.

The TR3 simulation is started from a spinup phase of the EQ1500 experiment (i.e., an adjustment phase from the
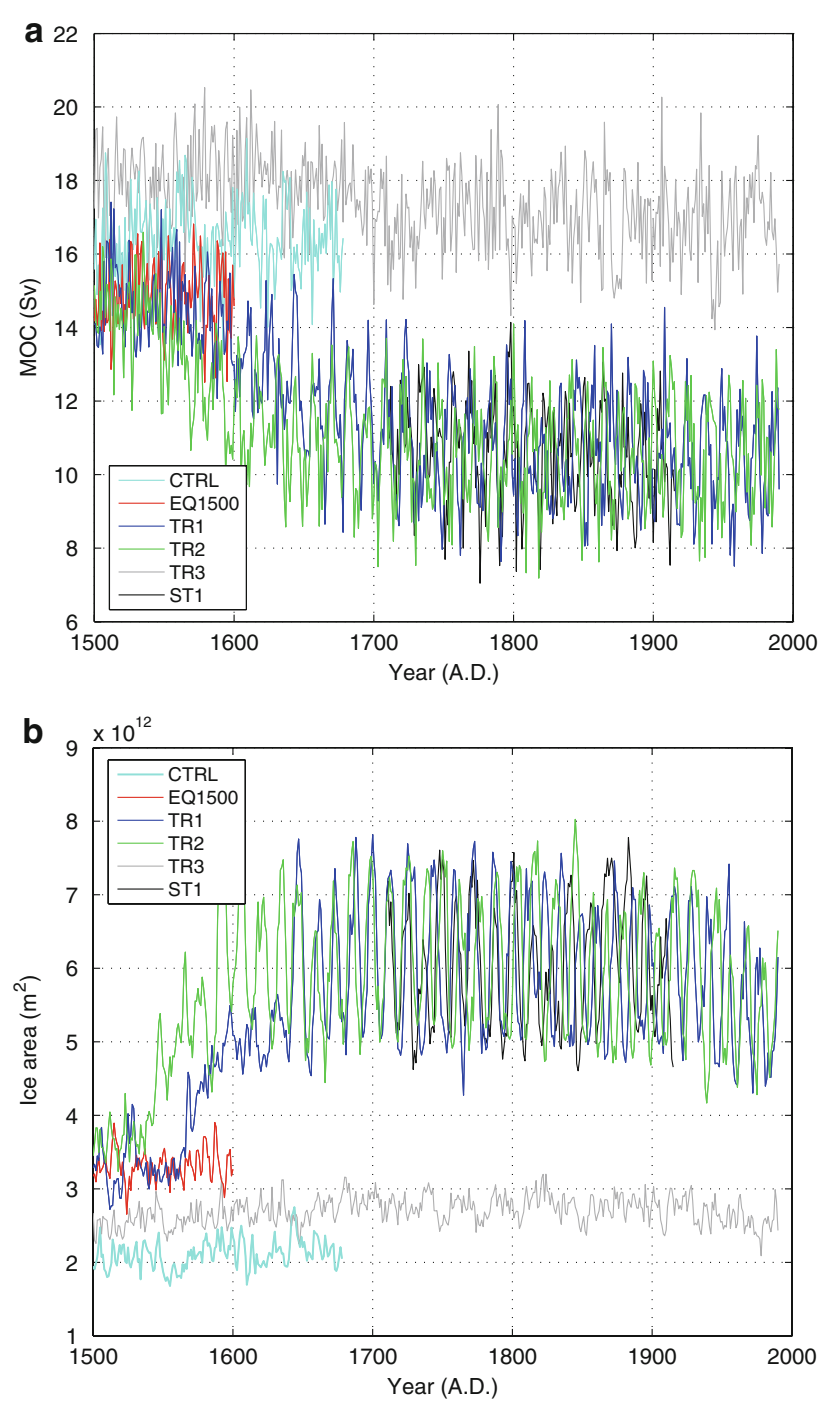

Fig. 3 Annual mean time series: a the maximum value of meridional overturning stream function in the North Atlantic (below $500 \mathrm{~m}$; north of $28^{\circ} \mathrm{N}$ ); and $\mathbf{b}$ sea ice area in the North Atlantic. Note that the Greenland-Iceland-Norwegian Seas are included. Note also that years in the abscissa only correspond to the TR1, TR2, and TR3 experiments because the forcings are held fixed interannually in other experiments

present-day to permanent 1500 A.D. forcing conditions), and contains some drift. Since an identical external forcing is applied to the TR1, TR2, and TR3 simulations, differences between the three are due to different initial conditions. The different timing of the MOC weakening between the TR1 and TR2 simulations (14.4 and $12.6 \mathrm{~Sv}$ for 1550-1599 average, respectively) also suggests that the weakening is not a result of a one-to-one response of MOC to external forcing. Rather, it suggests a threshold-crossing type response, in which the exact timing is influenced by unforced internal variability.

Figures $4 \mathrm{a}$ and $\mathrm{b}$ show 20-year averages around TR3 and TR1/TR2 initial conditions, respectively. The sea ice 
cover is expanded southward in the GIN Sea and off Newfoundland, and deep convection is less vigorous in the GIN Sea for the TR1/TR2 initial conditions. As shown later, the GIN Sea is completely capped by sea ice in winter, and the convection ceases there when the MOC is in the reduced state. We attribute the large reduction of MOC in the TR1 and TR2 experiments to unrealistically too cold initial conditions. Comparing the initial conditions of TR1 and TR2 experiments with proxy reconstructions, we find a cold bias. The CTRL simulation where we start our spinup has already a cold bias of about $1 \mathrm{~K}$. In addition, the equilibration of the initial conditions to 1500 A.D. forcing results in the inclusion of the so-called committed climate change (Yoshimori et al. 2006). As a result, the Northern Hemisphere temperature in the EQ1500 experiment is about $2.2 \mathrm{~K}$ colder than the CTRL simulation while the reconstructed 1500 A.D. was roughly $1 \mathrm{~K}$ colder than 1990 A.D. (Mann et al. 2008). Furthermore, there are large uncertainties in the forcing during this time period (Rind et al. 2004).

Although only the last 100 years of the integration were used for the analysis, the EQ1500 experiment exhibits a stable MOC state during the whole non-accelerated period of more than 200 years (and the last 50 years of the accelerated period, not shown). Therefore, continuing the EQ1500 run does not likely lead to the similar reduction as in TR1 and TR2 experiments, and the EQ1500 state may be close to but not beyond the "cold threshold". While the weakening of the MOC is not a focus of this study, one implication of these results is that the uncertainty in the initial conditions must be taken into account to assess realistic climate simulations for this time period, as also pointed out by González-Rouco et al. (2006).

Particularly interesting features of these results are the large variance and quasi-periodic fluctuations of MOC in the TR1 and TR2 simulations. The standard deviation of the MOC index in the CTRL, EQ1500, and TR3 experiments is about $1.1,0.9$, and $1.1 \mathrm{~Sv}$, respectively, whereas it is about $1.4 \mathrm{~Sv}$ in both TR1 and TR2 experiments. Here the standard deviations for the TR1, TR2, and TR3 simulations are calculated for the period of 1701-1990.

The corresponding time series of annual mean North Atlantic sea ice area are shown in Fig. 3b. The area covered by sea ice in the EQ1500 experiment is about 1.6 times larger than in the CTRL experiment. The increase of sea ice cover mainly occurs in the Greenland Sea, Denmark Strait, and Labrador Sea areas. The most striking response is seen in the TR1 and TR2 simulations. The average sea ice areas between 1701 and 1990 in these two runs are about 1.8 times larger than in the EQ1500 experiment. The simulated increase of sea ice cover from about mid sixteenth to late seventeenth centuries occurs almost
Fig. 4 Sea ice extent and mixed-layer depth in JanuaryFebruary-March. Colors represent average mixed-layer depth $(m)$ while thick lines represent sea ice cover of 15 , 30,60 , and $90 \%$ : a 20 -year average around TR3 initial conditions (years 955-974 in Fig. 1); b 20-year average around TR1 and TR2 initial conditions (years 1466-1485 in Fig. 1); c positive MOC composite with lag of -5 years; and d) positive MOC composite with lag of 1 year. See text and Fig. $6 \mathrm{a}$ for the construction of the MOC composite
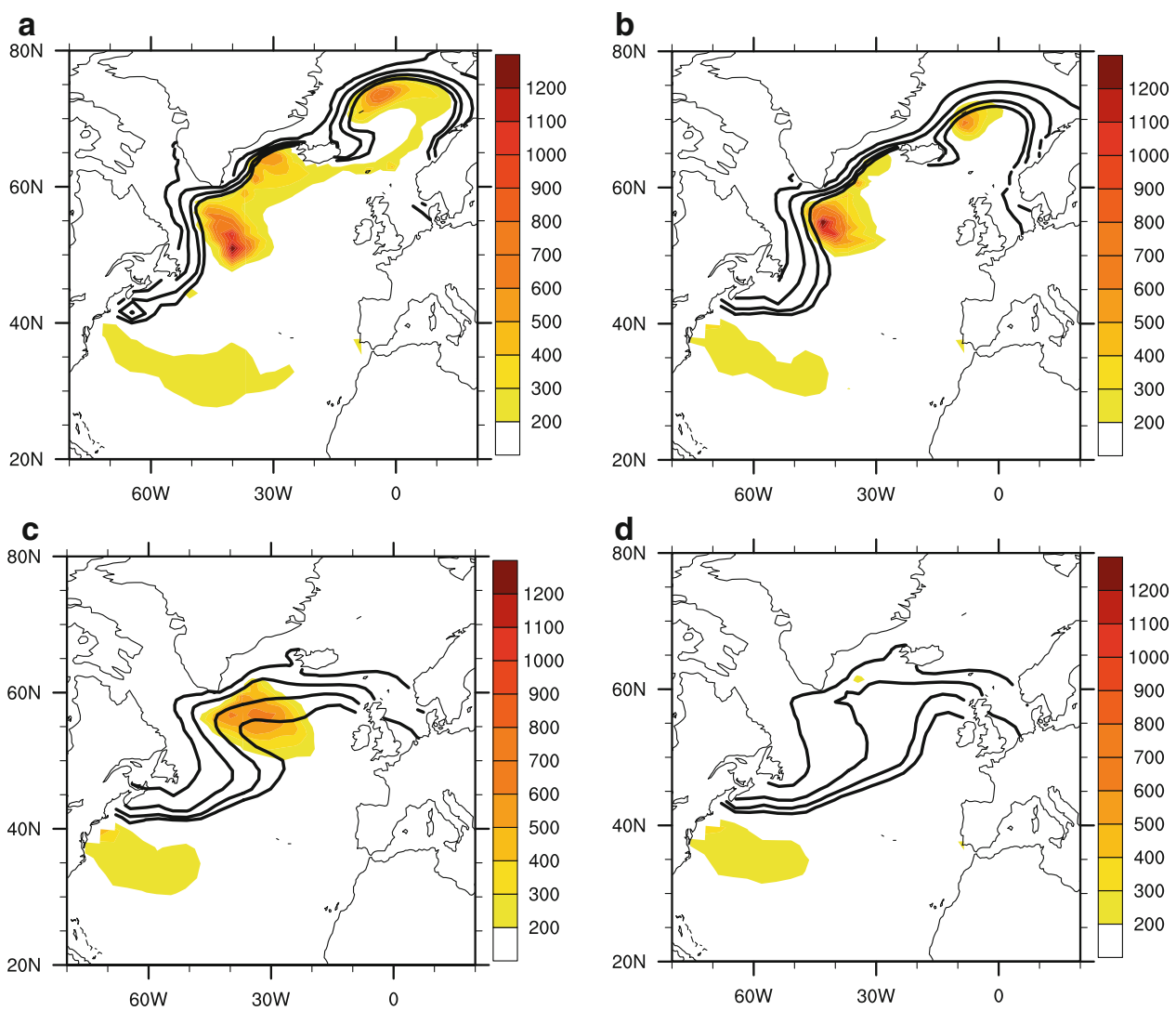
synchronously with the weakening of MOC. This suggests a strong link between the sea ice extent and the MOC response. Note that jumps in sea ice time series in mid sixteenth century do not coincide with the timing of volcanic eruptions. The increase of sea ice cover in the TR1 and TR2 experiments mainly occurs in the Norwegian and Labrador Seas with a southward extension in general. Another striking feature of the TR1 and TR2 experiments is the large amplitude of the oscillations. The standard deviation of sea ice area in the CTRL, EQ1500, and TR3 experiments is about $2.0 \times 10^{11}, 2.1 \times 10^{11}$, and $1.8 \times$ $10^{11} \mathrm{~m}^{2}$, respectively, whereas it is about $9.0 \times 10^{11} \mathrm{~m}^{2}$ in both TR1 and TR2 simulations. While it is of interest to explore the cause of the MOC weakening in detail, our primary interest here is the simulated decadal oscillations seen in both MOC and sea ice in the TR1 and TR2 simulations.

So far it is not clear whether the decadal oscillations are maintained by the external forcing or unforced internal variability. In order to distinguish these two possibilities, we use the additional experiment ST1 with initial conditions from the 1710 A.D. climate state of the TR1 simulation and permanent 1500 A.D. boundary conditions. In the absence of the time-varying external forcing, the oscillations continue to exist for the entire period of the integration more than 200 years (Fig. 3a, b). The standard deviations of the MOC index and North Atlantic sea ice area in the ST1 experiment are $1.4 \mathrm{~Sv}$ and $8.3 \times 10^{11} \mathrm{~m}^{2}$, respectively. These values are close to those of TR 1 and TR2 simulations, which confirm that the oscillations reflect internal atmosphere-ocean-sea ice variations and are not maintained by external forcing. The cross-spectral analysis shows that TR1, TR2, and ST1 MOC indices are not coherent at the $10 \%$ significance level (not shown), consistent with the above interpretation. It is worth noting that not only the oscillations of MOC and sea ice cover persist in experiment ST1, but also the mean strength of MOC and area of sea ice cover remain approximately unaltered after the external forcing is switched to the 1500 A.D. values. Since the external forcing in the EQ1500 and ST1 experiments is identical, this result suggests that this model has at least two different metastable states, which can persist for several centuries. This fact is more clearly depicted in Fig. 5 which shows that the global mean surface air temperatures in the EQ1500 and ST1 experiments stay stable with a difference of about $0.4 \mathrm{~K}$. It is important to stress that we do not claim that these stable states represent multiple equilibria because the integration period is too short to infer such a conclusion. The warming found in TR1 and TR2 experiments after 1850 is due to increased solar and GHG forcings (Fig. 2). Because the ST1 experiment is not influenced by the time-varying external forcing, the interpretation of that result is more straightforward than

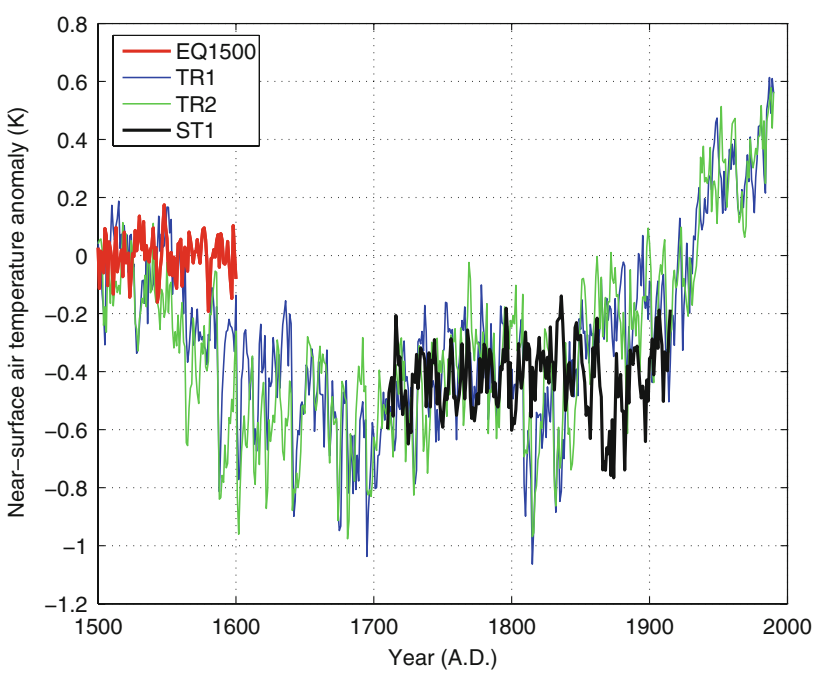

Fig. 5 Global and annual mean near-surface air temperature anomaly relative to the mean value of the EQ1500 experiment. Note that years in the abscissa only correspond to the TR1 and TR2 experiments

that of TR1 and TR2 experiments. For this reason, we primarily present the results from the ST1 experiment. It is very important to note, however, that the same analysis when applied to the TR1 and TR2 simulations exhibits essentially the same results as the ST1 analysis. The TR3 simulation is not discussed further.

To capture the main characteristics of the oscillations a composite analysis is applied to the North Atlantic meridional overturning stream function. The positive composite is constructed by averaging years when the MOC index exceeds +1 standard deviation while the negative composite is constructed by averaging years when the MOC index is below -1 standard deviation (Fig. 6a). The positive composite shows a sinking at about $50-60^{\circ} \mathrm{N}$ which penetrates deeper than 2,000 m (Fig. 6b). The negative composite shows a weak sinking which only reaches about 2,000 m (Fig. 6c). The Antarctic Bottom Water penetrates further north in the negative composite compared to the positive composite. The difference of the two composites clearly depicts the nature of the oscillations in which a large anomalous overturning cell of $5 \mathrm{~Sv}$ is seen well below the depth of 3,000 $\mathrm{m}$ and southward beyond the equator (Fig. 6d). Figure $4 \mathrm{c}$ and $\mathrm{d}$ show the composite with lags of -5 years and +1 year when the mixed layer is deepest and shallowest, respectively. The GIN Sea is covered by sea ice in winter and no convection occurs there in the MOC oscillatory mode. Also, the MOC oscillation accompanies substantial variations in sea ice cover and convection near the Irminger Sea.

Probably the most interesting feature of the oscillations is that they have a fairly narrow spectral peak of about 13 years (Fig. 7a). Thus, these oscillations form welldefined decadal variability. The auto-correlation function 
Fig. 6 Composite analysis for the oscillations of the Atlantic meridional overturning circulation in the ST1 experiment (1710-1915): a standardized MOC index, $\mathbf{b}$ positive composite (red circles in a), c negative composite (blue circles in $\mathbf{a}$ ); and $\mathbf{d}$ the difference between $\mathbf{b}$ and $\mathbf{c}$.

Note that years in the abscissa do not correspond to the actual calendar date in $\mathbf{a}$, but are used for the comparison with previous figures. Ordinates represent depth in meter in b-d. Contour intervals are $1 \mathrm{~Sv}$ in $\mathbf{b}$ and $\mathbf{c}$, and $0.5 \mathrm{~Sv}$ in $\mathbf{d}$. The standardized MOC index is defined as MOC minus mean divided by its standard deviation
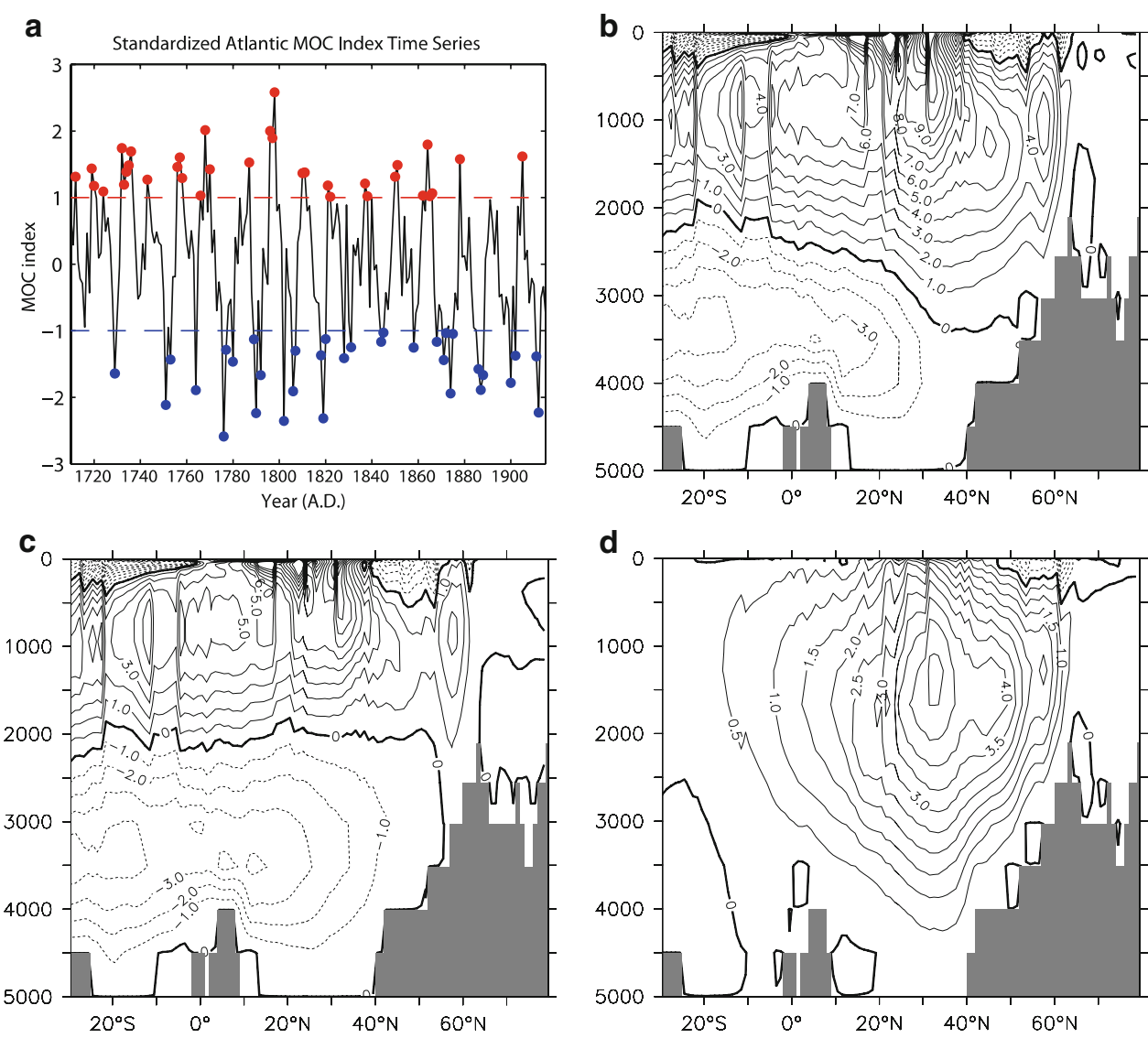

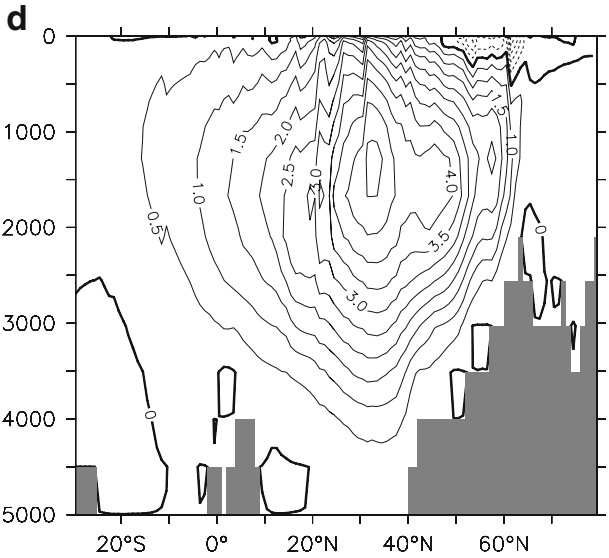

in Fig. $7 \mathrm{~b}$ shows a remarkable contrast between oscillations simulated in relatively cold climates (TR1, TR2, and ST1) and relatively warm climates (CTRL and EQ1500). There is no well-defined periodicity in the latter. Again, since the boundary conditions in the EQ1500 and ST1 experiments are identical, the results imply that this model has two completely different quasistable solutions for the MOC and the sea ice: one with a relatively strong stable circulation, and the other with a weak oscillatory solution. Note that the two quasistable solutions are found under the 1500 A.D. forcing, which leads to colder climates than present-day forcing.

\subsection{Linear regression analysis of the MOC index}

To illustrate the nature of this oscillating behavior of the MOC a lag-regression analysis is performed, in which interested variables are linearly regressed onto the MOC index with lags from -8 to +8 years (Press et al. 1992, pp. 655-660). The result for the ST1 experiment is presented in Fig. 8. The MOC index exhibits a peak negative phase at about 6-7 years before a peak positive phase (defined here as lag 0 year). The increased sinking around $60^{\circ} \mathrm{N}$ starts at lag of about -4 years, and the sinking water gradually extends to the south thereafter. At lag of about
+2 years, the reduction of the sinking is seen. While the strict timing differs in each cycle, we are fairly confident about the robustness of the results of the regression analysis because all TR1, TR2, and ST1 experiments show the same features. Note that the regression analysis with lag 0 year (center plot in Fig. 8) shows a very similar pattern with the difference in the composite analysis (Fig. 6d), suggesting linearity of the oscillation.

Figure 9 shows correlation coefficients between annual and zonal mean density and the MOC index with lags from -6 to +6 years in the ST1 experiment (Press et al. 1992, pp. 630-633). Here correlation rather than regression coefficients are shown for display purposes, accommodating a wide range of density anomalies over depth. A linear detrending is applied before calculating the correlation in order to eliminate a small long-term trend at greater depth. The global mean temperature and salinity trends are linear, $0.07 \mathrm{~K}$ and $-3.4 \times 10^{-4}$ per century, respectively, and the application of a cubic smoothing spline with a cutoff period of 30 years for the detrending yields essentially the same results. The positive sinking anomaly around $60^{\circ} \mathrm{N}$ starts at lag of about -4 years (Fig. 8). It corresponds to the concurrent positive density anomaly in that region. With time, the positive density anomaly gradually spreads southward. The negative sinking anomaly around $60^{\circ} \mathrm{N}$ starts at lag of 

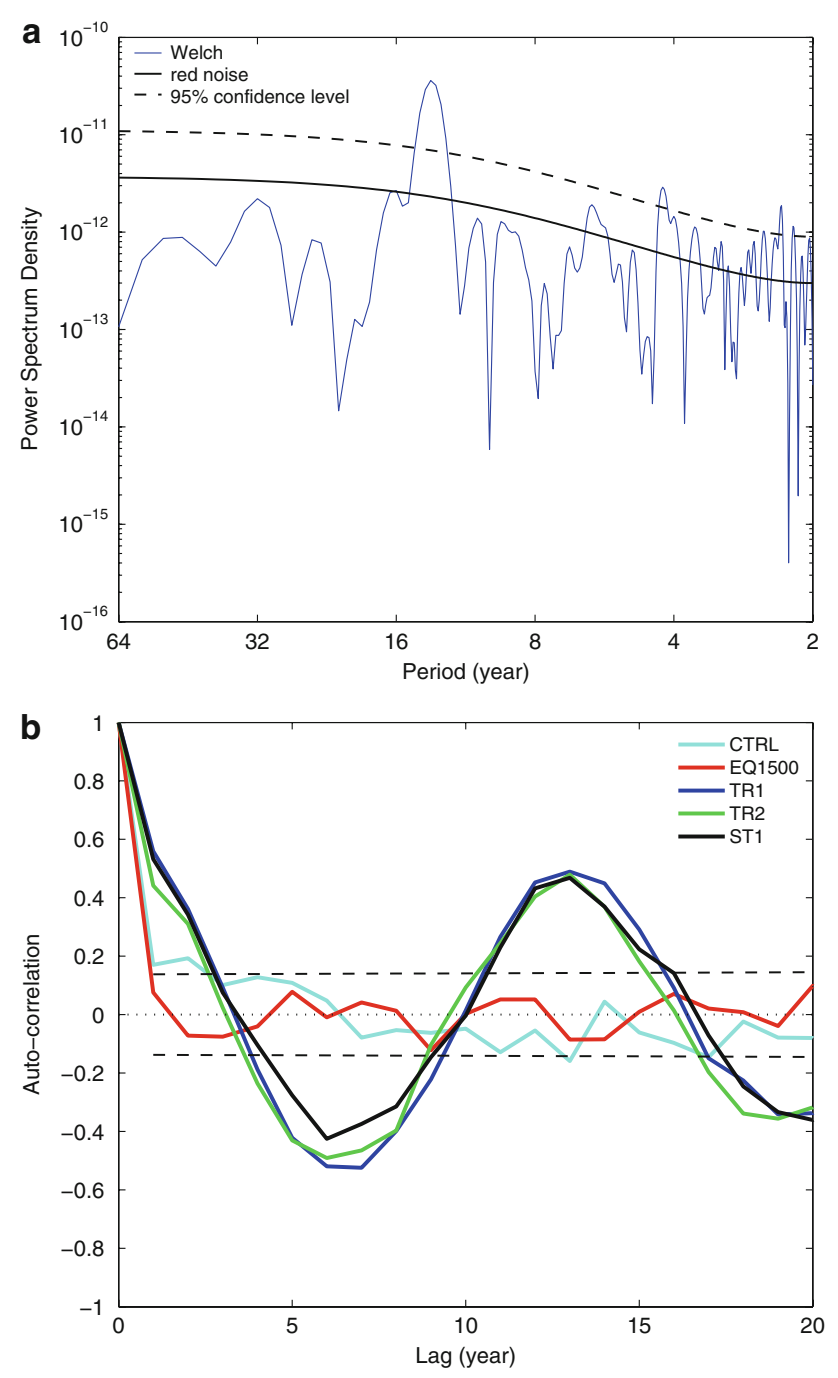

Fig. 7 a Spectrum of the Atlantic MOC index in the ST1 experiment, and $\mathbf{b}$ auto-correlation function of the Atlantic MOC index in each experiment. In a, power spectrum density is computed using Welch's method with $50 \%$ overlap and applying a Hann window. Red noise and $95 \%$ confidence level is calculated following Torrence and Compo (1998). In b, 95\% confidence interval is indicated by dashed lines which are calculated assuming white noise

about +2 years (Fig. 8) and corresponds to the concurrent negative density anomaly in that region. While the positive density anomaly dominates in the deep North Atlantic at lag of 0 years, it is noticeable that a large negative density anomaly already occurs near the surface around $50^{\circ} \mathrm{N}$. The distinct meridional density gradient seen in the course of the oscillation cycles drives the anomalous MOC (Hughes and Weaver 1994; Thorpe et al. 2001). A similar figure but for correlation coefficients with temperature or with salinity shows very similar spatial patterns to density with opposite signs except for the near-surface (not shown). This result indicates that the anomalous density structure is mainly determined by the temperature anomaly. This is, however, not the case for the near-surface density anomaly.
Figure 10 shows regression coefficients between annual mean surface density and the MOC index. Note that the effective sample size is estimated using the formula of Bretherton et al. (1999, Eq. 30) in computing the statistical significance, but the results are not sensitive to the choice of the formula (e.g., Wilks 1995, Eq. 5.12, von Storch and Zwiers 1999, Eq. 6.25, or the use of actual sample size). A large positive surface density anomaly is seen in the northern North Atlantic at lag of about -4 years. This density anomaly is also captured in the zonal mean correlation coefficients in Fig. 9, and is reflected as an increase in mixed-layer depth (convection) and a lowering of sea surface height in that region (not shown). A delay in the peak of the MOC with respect to the surface density anomaly of a few years was also reported in previous studies (Timmermann et al. 1998; Dai et al. 2005; Dong and Sutton 2005; Danabasoglu 2008). With time, the density anomaly in this region becomes negative with a peak at lag of about +1 year, and then becomes positive again at lag of about +6 years. In Fig. 10, the density anomaly starts around $50-55^{\circ} \mathrm{N}$ and is then advected to the northeast. The regression coefficients with temperature or salinity show nearly identical patterns of the same signs as the regression coefficients with density (not shown). This suggests that the surface density anomaly is determined by salinity anomaly, rather than temperature anomaly. Similar regression patterns of surface density, temperature, and salinity are clearly visible to the depth of about $100 \mathrm{~m}$. The question is then how this near-surface salinity anomaly, which controls the density anomaly, is maintained.

A lag-correlation analysis is applied to key variables averaged over the upper $100 \mathrm{~m}$ of the region indicated in Fig. 11a and the MOC index (Fig. 11b). The region is chosen in reference to Fig. 10 and complies with the configuration of the irregular model grid. Additionally we show correlation coefficients of net surface heat flux and net freshwater flux converted to virtual salt flux with the MOC index (positive values correspond to fluxes into the ocean). Furthermore, the auto-correlation function of the MOC index is shown as a reference. As mentioned above, density, salinity, and temperature covary in a similar fashion with peak positive and negative anomalies at lag of -5 and +1 years, respectively. The fact that the surface salt flux lags behind the salinity anomaly suggests that the salinity anomaly is not driven by the surface freshwater flux. Note that the net surface freshwater flux anomaly primarily reflects the meltwater flux anomaly from sea ice. The meltwater flux anomaly is reduced when the SST is warm, sea ice is decreased, and the southward freshwater transport through formation and melting of sea ice is reduced. The net surface heat flux essentially exhibits opposite signs to the temperature anomaly, that is, the surface heat flux from the ocean increases when SSTs are 

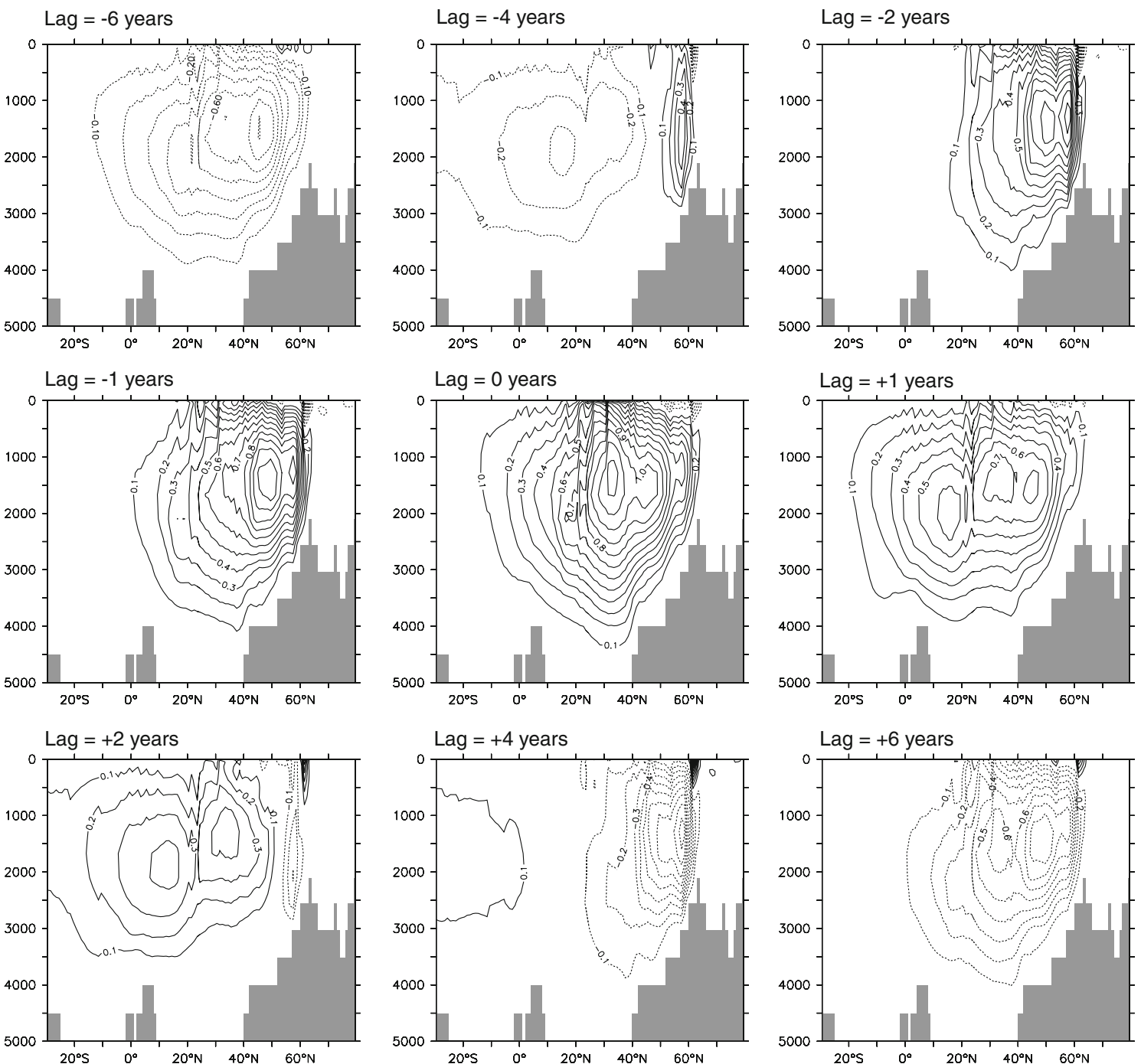

Fig. 8 Annual mean Atlantic meridional overturning stream function regressed onto the MOC index with lags $-6,-4,-2,-1,0,+1,+2$, +4 , and +6 years in the ST1 experiment. Ordinate represents depth in meter. Contour intervals are $0.1 \mathrm{~Sv} / \mathrm{Sv}$, and zero contours are omitted for clarity

influx by $90^{\circ}$ in phase, Fig. 11c suggests the peak salinity anomaly at a lag of about +7 (or -6 ) years. The actual peak of salinity anomaly occurs another year or so later (lag of -5 years) in Fig. 11b. We speculate that this delay may be due to a positive convective feedback, in which the surface salinity is enhanced by the entrainment of more saline water from below, which in turn delays the timing of the peak salinity anomaly. Note that warm and saline subtropical water penetrates less far north; cold and fresh Nordic and Labrador Sea water spreads further south in the cold and reduced MOC state than in CTRL, and the surface subpolar gyre is much fresher.

Once the advective salt flux is recognized as important, it is of interest to know which direction the anomalous salt flux comes from. A simple decomposition of the advective salt flux anomaly into individual sides of the region can be 

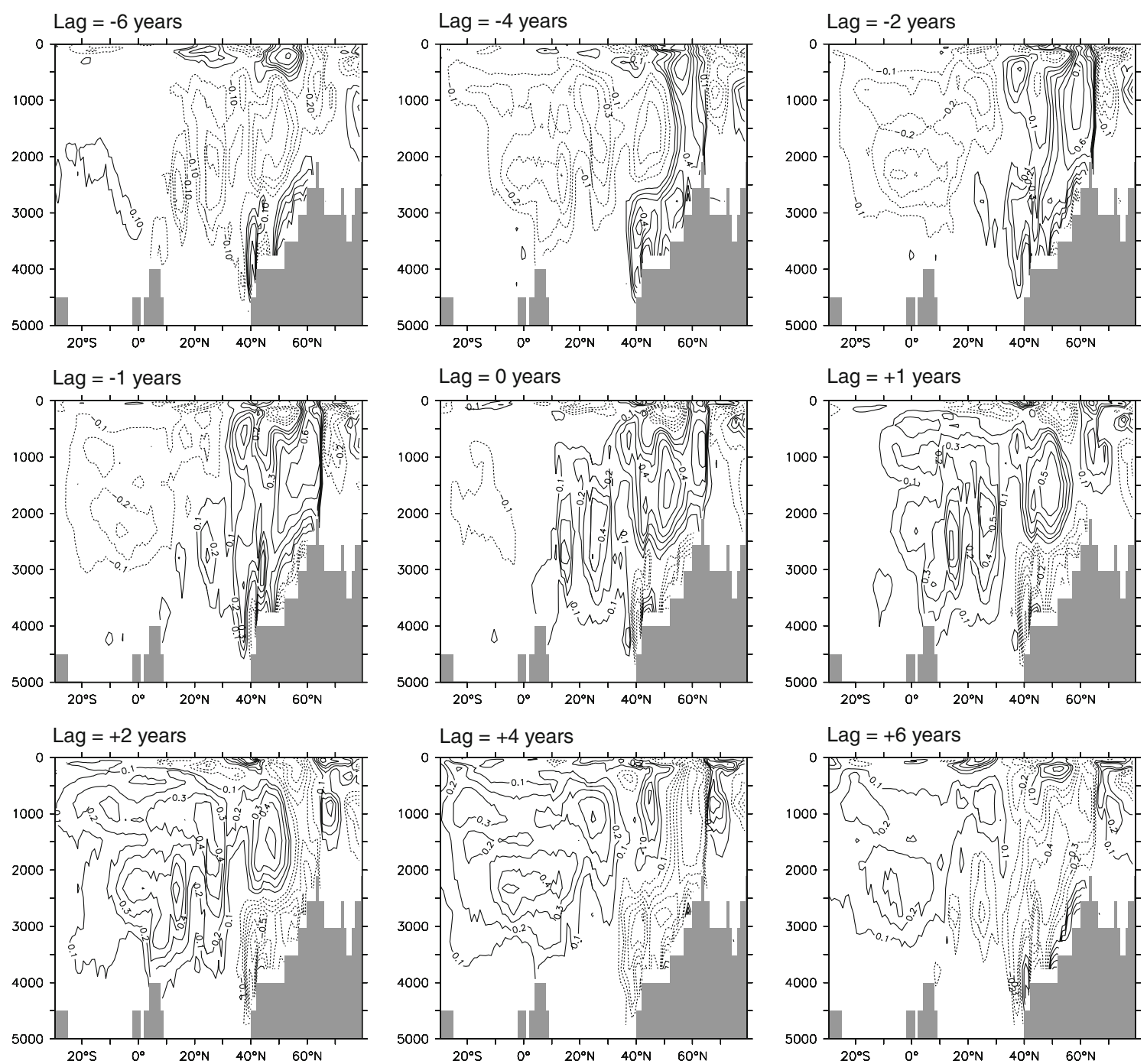

Fig. 9 Correlation coefficients between annual and zonal mean in-situ density and the MOC index in the Atlantic Ocean with lags $-6,-4,-2,-1,0,+1,+2,+4$, and +6 years in the ST1 experiment. Ordinate represents depth in meter. Contour intervals are 0.1 , and zero contours are omitted for clarity

used monthly mean fields. The method is somewhat crude, but the total advective salt influx anomaly indicated in Fig. 11d agrees reasonably well with the net advective salt flux indicated in Fig. 11c. This analysis suggests that the salinity transport from the west side of the region dominates in determining the salinity anomaly in the region (Fig. 11d). This is in agreement with the regression analysis of the barotropic stream function, a vertically integrated transport over all depth, onto the MOC index. The analysis suggests that the transport of fresher Labrador Sea near-surface water from the west to the region is increased and decreased with lag of about -4 and +2 years, respectively (Fig. 12c, d; compare with Fig. 10). Additionally it shows that the positive salinity anomaly leaves the region from the east side when the negative salinity anomaly enters the region from the west side. 

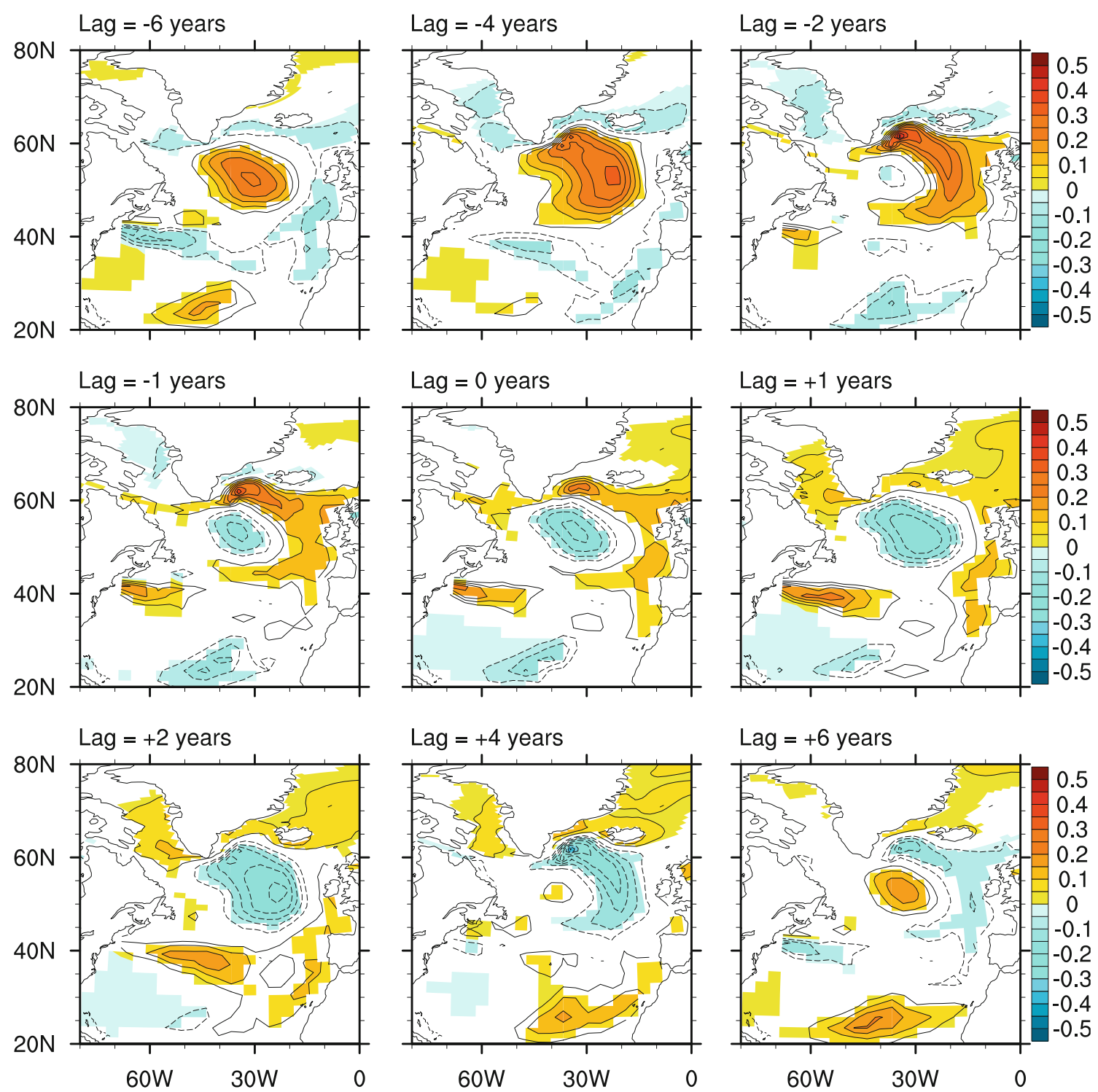

Fig. 10 Annual mean sea surface density regressed onto the MOC index with lags $-6,-4,-2,-1,0,+1,+2,+4$, and +6 years in the ST1 experiment. Contour intervals are $0.05 \mathrm{~kg} \mathrm{~m}^{-3} / \mathrm{Sv}$, and zero

contours are omitted. Values that are statistically significant at 5\% level (of falsely rejecting the null hypothesis) are colored

In summary, the positive surface salinity and density anomalies develop in the northern North Atlantic about 45 years before the peak MOC strength. These anomalies enhance the convective activity, and are advected to the northeast towards the Irminger Sea by mean circulation. The advected surface density anomaly lowers the sea surface height and induces an anomalous cyclonic circulation via geostrophic adjustments. This anomalous circulation brings fresher Labrador Sea near-surface water into the northern North Atlantic where the original salinity anomaly is located. It gradually freshens the region. When the MOC reaches the peak strength, the surface freshening is already proceeding, and the density anomaly in the northern North Atlantic attains a minimum 1-2 years after the peak MOC strength. These processes take about 6-7 years, and constitute a half cycle of the oscillation.

\subsection{Link to the North Atlantic Oscillation}

We now turn to the influence of wind stress anomalies in the North Atlantic. In Fig. 12a and b, the wind stress curl regressed onto the MOC index is presented over the ocean. Note that they are evaluated using stresses exerted on the sea surface, and thus include the minor effect of sea ice. Since the positive anomalies of wind stress curl tend to spin up the cyclonic gyre circulation and vice versa, the anomalous wind stress curl in Fig. 12a and b tends to amplify the gyre circulation anomalies in Fig. 12c and d, 

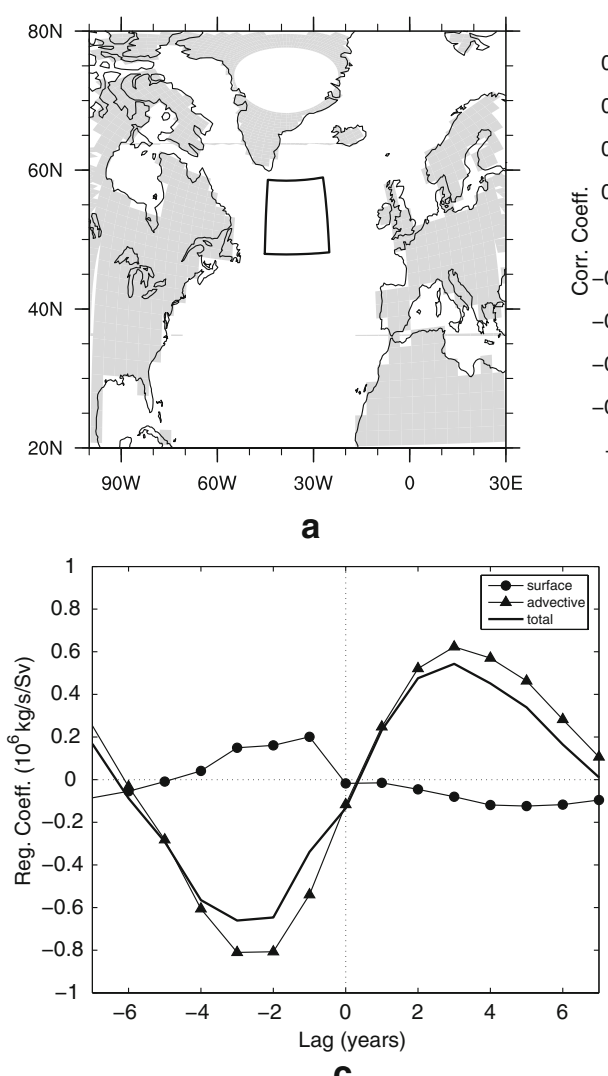

C

Fig. 11 Budget analysis in a North Atlantic region: a the region used in the budget analysis (upper $100 \mathrm{~m}$ ); b lag-correlation coefficients with the MOC index for density, temperature, salinity, surface heat flux, and surface (virtual) salt flux; also plotted are correlation coefficients for the MOC index itself; note that positive fluxes correspond to fluxes into the ocean; c lag-regression coefficients with the MOC index for (virtual) salt flux through the surface, advective

respectively. Thus, a possible wind stress influence on the subpolar gyre circulation anomaly is suggested.

To understand the anomalous wind patterns associated with the MOC oscillations, winter (December to February) mean sea level pressure is regressed onto the MOC index (Fig. 13). Note that annual mean sea level pressure shows similar patterns with weaker magnitudes. The patterns resemble the NAO having a north-south dipole anomaly. While the centers of sea level pressure anomalies vary with lags, some of them are very close to the centers of action for the typical NAO pattern, i.e., Iceland and Azores. Hereafter we call this pattern NAO for convenience without rigorously quantifying the resemblance. The phase of the NAO tends to be negative from lags of -6 to -1 years, it switches to positive when the MOC has its peak strength, and stays in the positive phase until lags of about +6 years. Since this feature is also seen in TR1 and TR2 experiments, it is clear that there is a link between the simulated MOC oscillations and the NAO.
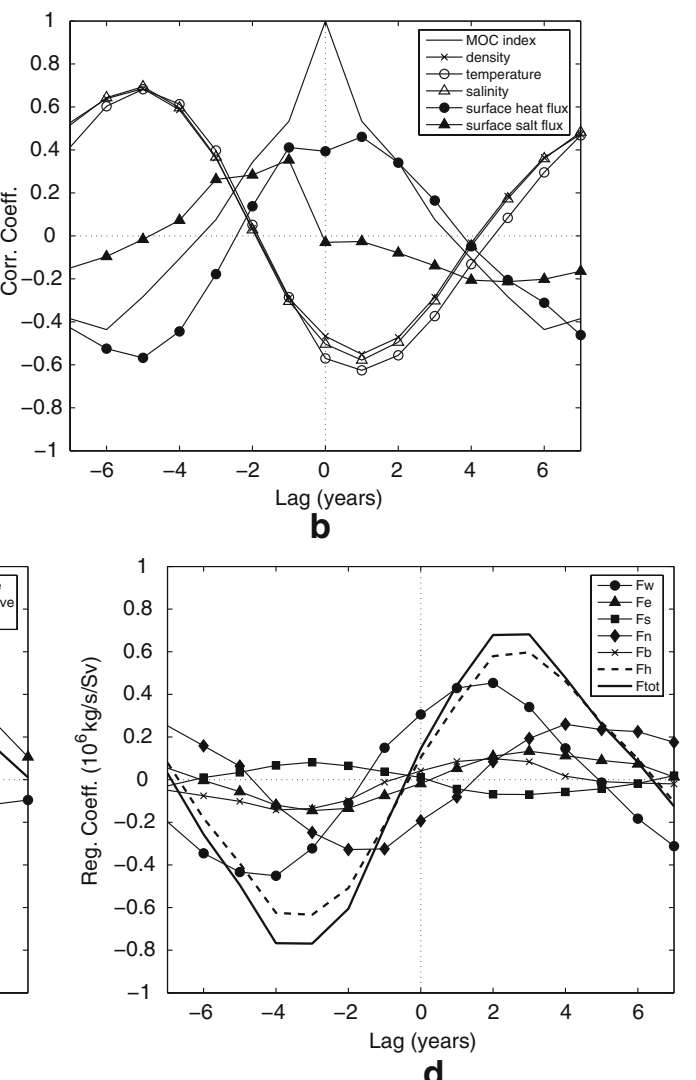

salt flux into the region (sum of the horizontal and vertical), and the sum of the surface and advective salt fluxes; d lag-regression coefficients with the MOC index for advective salt influx anomaly (see text for details); $F_{\mathrm{w}}, F_{\mathrm{e}}, F_{\mathrm{s}}, F_{\mathrm{n}}, F_{\mathrm{b}}$ are salt influx anomaly from the west, east, south, north, and bottom $(100 \mathrm{~m})$, respectively. $F_{\mathrm{h}}$ $\left(=F_{\mathrm{w}}+F_{\mathrm{e}}+F_{\mathrm{s}}+F_{\mathrm{n}}\right)$ and $F_{\text {tot }}\left(=F_{\mathrm{h}}+F_{\mathrm{b}}\right)$ are horizontal and total salt influx anomalies, respectively

To further understand the link between the MOC and the NAO, we performed an empirical orthogonal function (EOF) analysis on sea level pressure for a domain of $90^{\circ} \mathrm{W}-40^{\circ} \mathrm{E}$ and $20-70^{\circ} \mathrm{N}$. The leading EOF pattern for annual mean sea level pressure of the ST1 experiment exhibits a NAO-like dipole pattern in the North Atlantic (Fig. 14a). Note that the domain is expanded for display purposes by regressing Northern Hemisphere sea level pressure onto the leading principal component (PC1). The PC1 exhibits a marginally statistically significant spectral peak (Fig. 14b) near the decadal peak of the MOC index (Fig. 7a). To investigate the NAO influence on the ocean circulation anomaly, the barotropic stream function is regressed onto the PC1 with zero lags (Fig. 14c). The regression pattern suggests a possible influence of the NAO on the subpolar gyre circulation, particularly near the Irminger Sea. Therefore, changes of the NAO phase may play a role in the cycle of the MOC oscillations. When the $\mathrm{NAO}$ is in an anomalously positive phase, the circulation 
Fig. 12 Annual mean wind stress curl regressed onto the MOC index with lags -4 (a) and +2 (b) years in the ST1 experiment; and annual mean barotropic stream function regressed onto the MOC index with lags -4 (c) and +2 (d) years in the ST1 experiment. Contour intervals are 0.4 $\times 10^{-8} \mathrm{Nm}^{-3} / \mathrm{Sv}$ in (a) and (b) and $0.4 \mathrm{~Sv} / \mathrm{Sv}$ in (c) and (d).

Zero contours are omitted
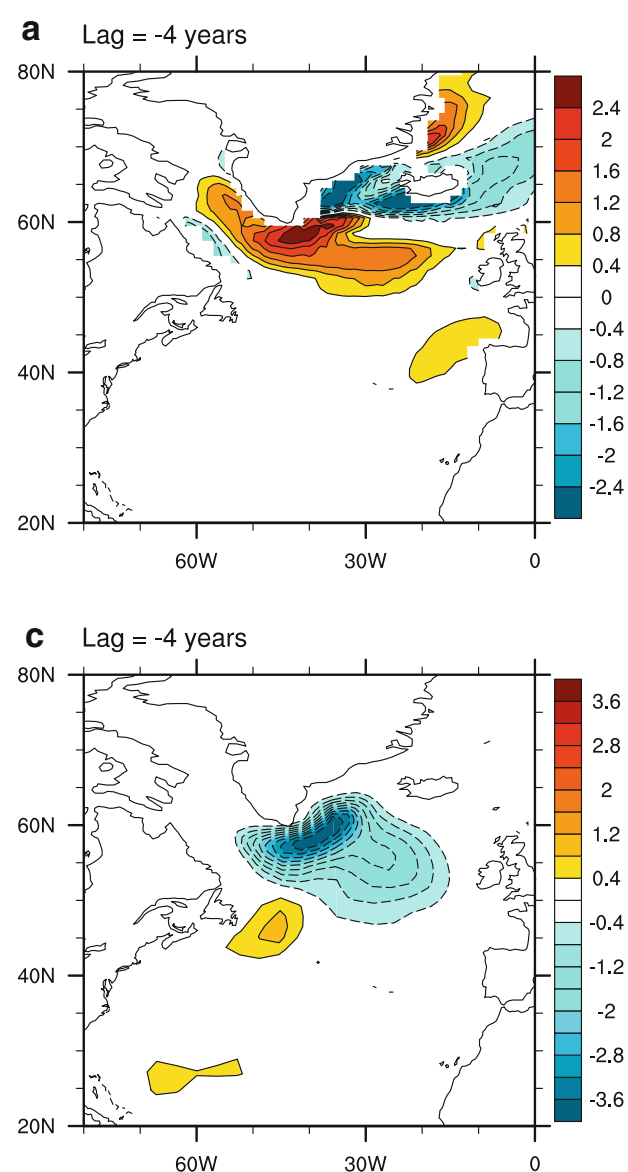
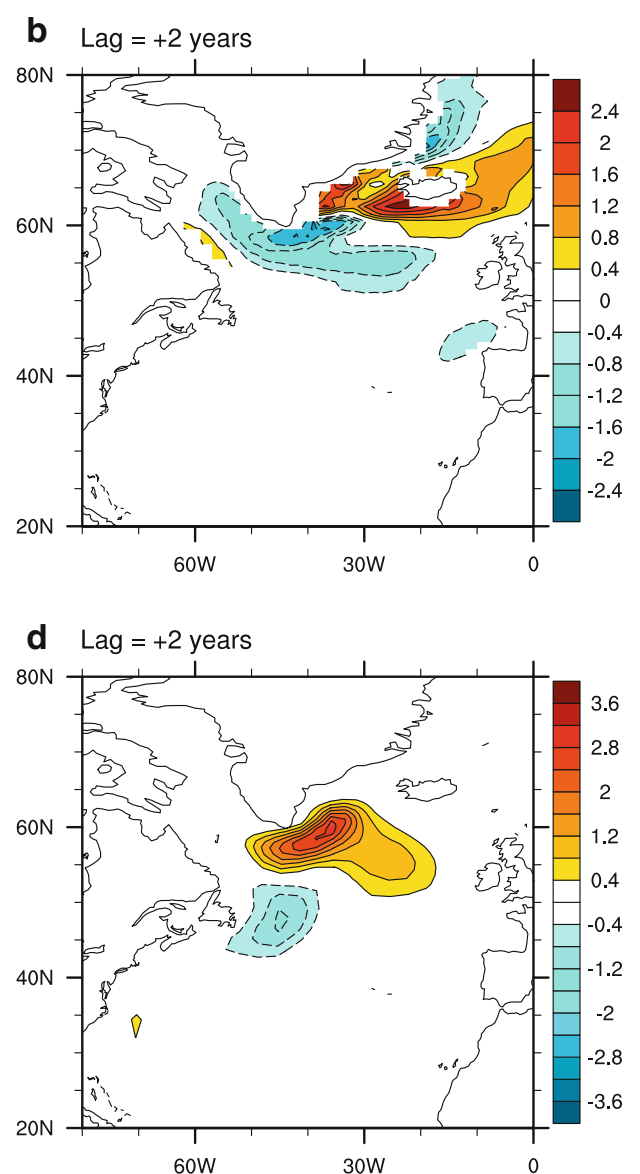

anomaly near the Irminger Sea tends to be clockwise, which in turn reduces the fresh water transport from the Labrador Sea. Since there is a correlation between the $\mathrm{NAO}$ and the MOC, it is not straightforward to completely separate the effect of the NAO and the effect of the MOC on other variables. Therefore, the NAO-specific effect on the circulation anomaly is not quantified here.

The regression patterns of surface temperature (sea or ice surface temperature) suggest that the NAO phase varies with surface temperature anomalies or an anomalous surface temperature gradient. When the meridional temperature gradient around $45-55^{\circ} \mathrm{N}$ is small, NAO tends to be in a negative phase and vice versa. Figure $15 a$ and $b$ show regression patterns of winter surface temperature without lags onto the PC1 of winter sea level pressure and the MOC index, respectively. Figure 15a indicates that the positive NAO tends to increase the meridional surface temperature gradient. The cooling in the northern part is accompanied by an increase in sea ice. The surface temperature anomalies could also feedback to the NAO by generating an equivalent barotropic response downstream of the anomalies: a low-pressure equivalent barotropic response by a negative SST anomaly and vice versa (Peng and Whitaker 1999; Walter et al. 2001; Kushnir et al. 2002; Magnusdottir et al. 2004; Deser et al. 2004).
Figure 16a shows north-south differences in geopotential height at three different levels. It approximately exhibits the equivalent barotropic structure with slightly stronger response at upper levels. Figure $15 \mathrm{~b}$ indicates that the peak MOC strength is accompanied by a warming between 40 and $50^{\circ} \mathrm{N}$ in the western North Atlantic, and a cooling between 50 and $60^{\circ} \mathrm{N}$ in the northern North Atlantic. The warming is brought by the increased northward heat transport with a maximum of about $0.06 \mathrm{PW} / \mathrm{Sv}$ near $30^{\circ} \mathrm{N}$ (cf. 0.67 PW in CTRL and 0.45 PW in ST1). Although the magnitude is larger, the statistical significance of the northern cooling is marginal due to large variations in this region associated with sea ice.

The meridional temperature gradient or baroclinicity is generally associated with transient eddy activity around this region. The transient eddy or storm track activity varies with the meridional surface temperature gradient when regressed onto the MOC index. Figure $16 \mathrm{~b}$ shows regionally-averaged regression coefficients of the sea level pressure and the synoptic eddy activity with the MOC index. The synoptic eddy activity is evaluated by a standard deviation of the band-pass (2.5 to 6 days) filtered geopotential height at $500 \mathrm{hPa}$ (Blackmon 1976). The signs of the regression coefficients for the north-south sea level pressure difference and the synoptic eddy activity covary in 

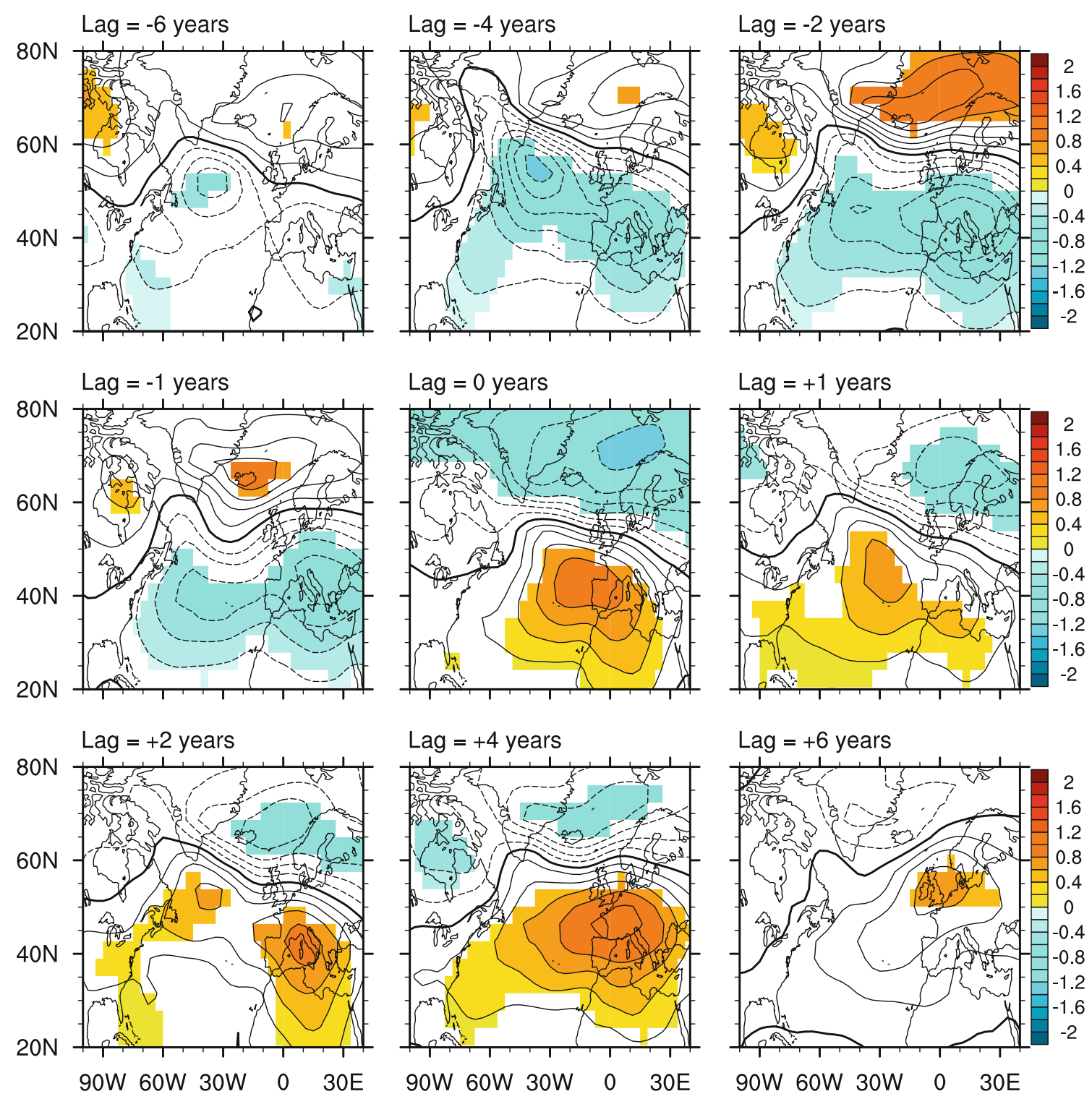

Fig. 13 Winter sea level pressure regressed onto the Atlantic MOC index with lags $-6,-4,-2,-1,0,+1,+2,+4$, and +6 years in the ST1 experiment. Contour intervals are $0.2 \mathrm{hPa} / \mathrm{Sv}$. Values that are

Fig. 16b. Note that the eddy statistics were not computed for the TR1 and TR2 experiments because the high-frequency data are unavailable. Also plotted are regression coefficients with the divergence of horizontal components of Hoskins' E-vector (Hoskins et al. 1983): $\mathbf{E}_{h}=\left(v^{\prime 2}-\right.$ $\left.u^{\prime 2},-u^{\prime} v^{\prime}\right)$, at $250 \mathrm{hPa}$ with the MOC index. Here $u^{\prime}$ and $v^{\prime}$ are band-pass filtered zonal and meridional velocity components, respectively. Divergence of $\mathbf{E}_{h}$ indicates a forcing of mean horizontal circulation consistent with a tendency to increase the westerly mean flow (Hoskins et al. 1983). Strictly speaking, the horizontal component of the $\mathbf{E}$-vector represents only a barotropic forcing on the westerly acceleration, but it is reasonable to use this diagnostic variable here considering the approximate barotropic response statistically significant at $5 \%$ level are colored. Here, winter is defined as an average of December-January-February, and years for winter averages are equal to those of January

(Fig. 16a). The signs of the regression coefficients for the synoptic eddy activity and the westerly acceleration covary in Fig. 16b. These results are consistent with the interpretation that the increased (decreased) surface temperature gradient induced by the changes in the MOC and the NAO enhances (weakens) synoptic eddy activity, and contributes to a convergence (divergence) of westerly momentum fluxes which is reflected in the north-south sea level pressure difference. Moreover, a storm track maximum located in the south of an SST anomaly reinforces the equivalent barotropic response downstream of the anomaly and helps in persisting the NAO phase (Walter et al. 2001; Luksch et al. 2005). With the experiments conducted here alone, it is not, however, possible to clearly separate the cause and 
a
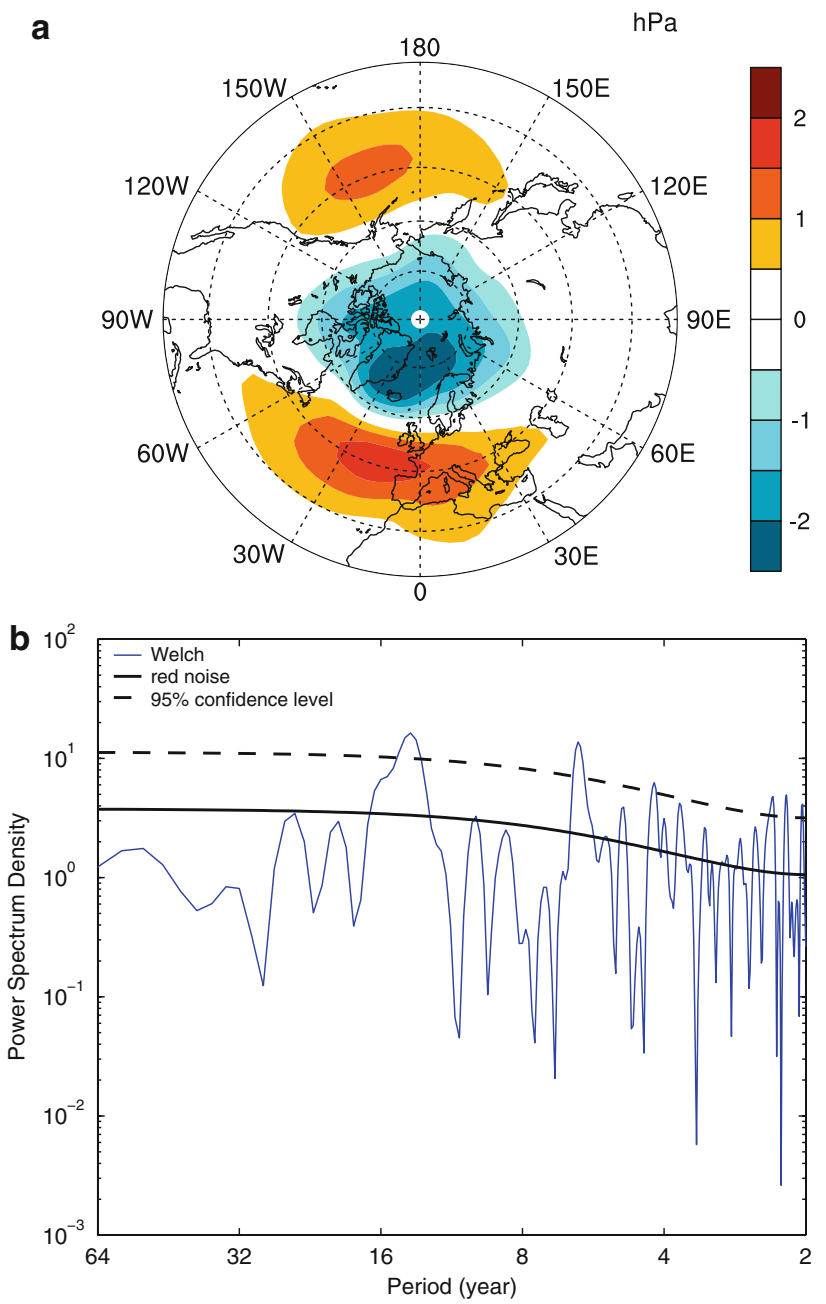

c

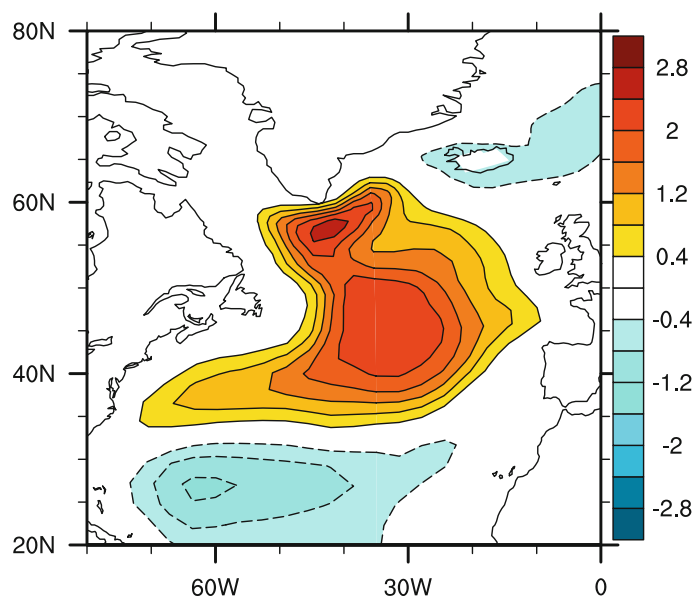

Fig. 14 a The spatial pattern obtained by regressing Northern Hemisphere sea level pressure onto the (standardized) leading principal component. The EOF analysis is conducted for annual mean sea level pressure in $90^{\circ} \mathrm{W}-40^{\circ} \mathrm{E}$ and $20-70^{\circ} \mathrm{N}$; b same as in Fig. 7a but for the leading principal component; and $\mathbf{c}$ regression pattern of annual mean barotropic stream function onto the PC1 (NAO) (Sv). The figures are for the ST1 experiment
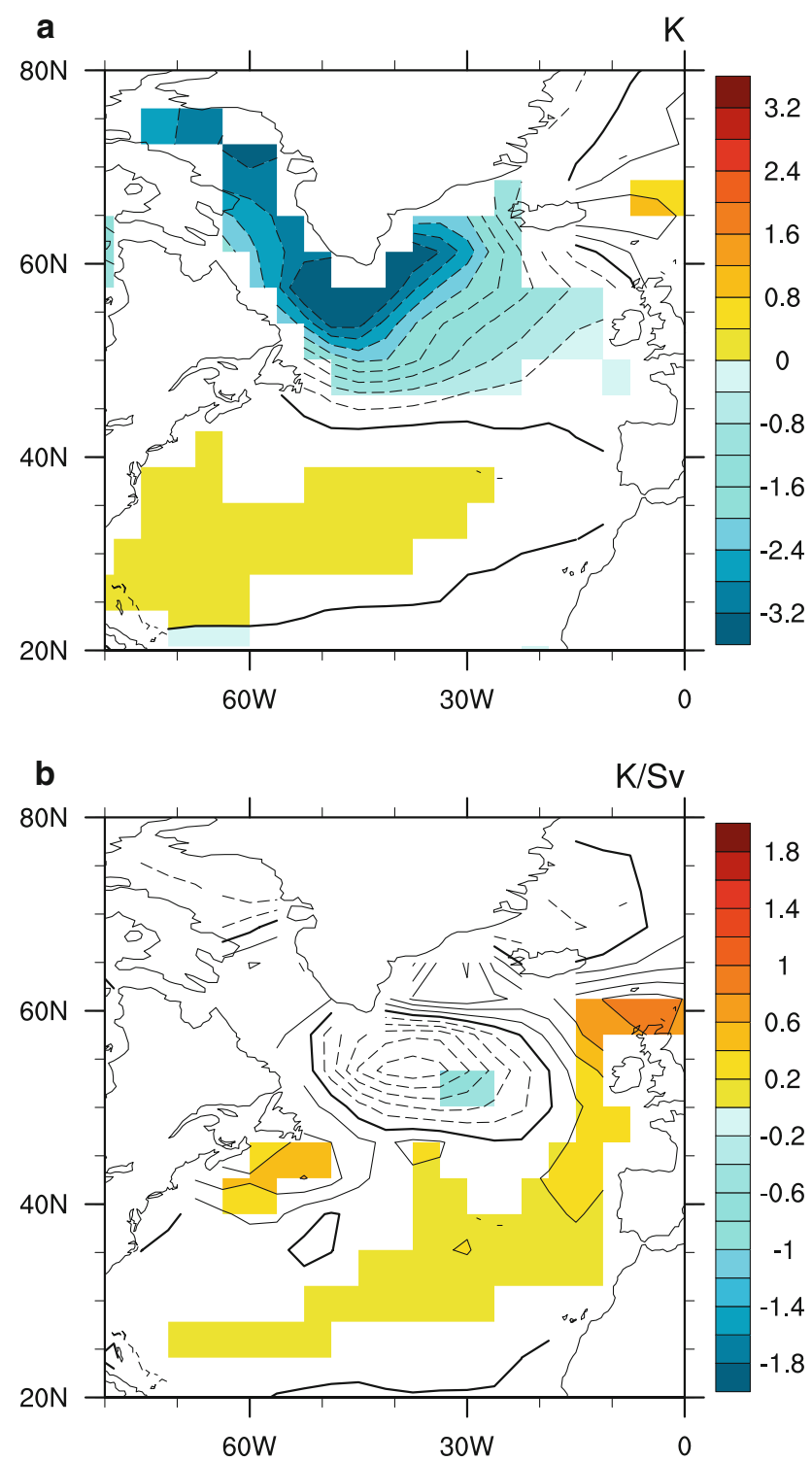

Fig. 15 Regression patterns of winter surface temperature in the ST1 experiment: a regressed onto standardized PC1 of winter sea level pressure without lags $(\mathrm{K})$; and $\mathbf{b}$ regressed onto the MOC index $(\mathrm{K} /$ $\mathrm{Sv}$ ). Notice that units are different in these two figures. Values that are statistically significant at $5 \%$ level are colored

effect among the NAO, synoptic eddy activity, and convergence of zonal momentum fluxes. Nevertheless, the simulated MOC oscillations have a clear link with phases of the NAO, which involves high-frequency eddy activity.

\section{Discussion and conclusions}

The two quasistable states and the oscillatory solution of the MOC identified in a fully coupled GCM are of great theoretical interest. However, the practical significance of 

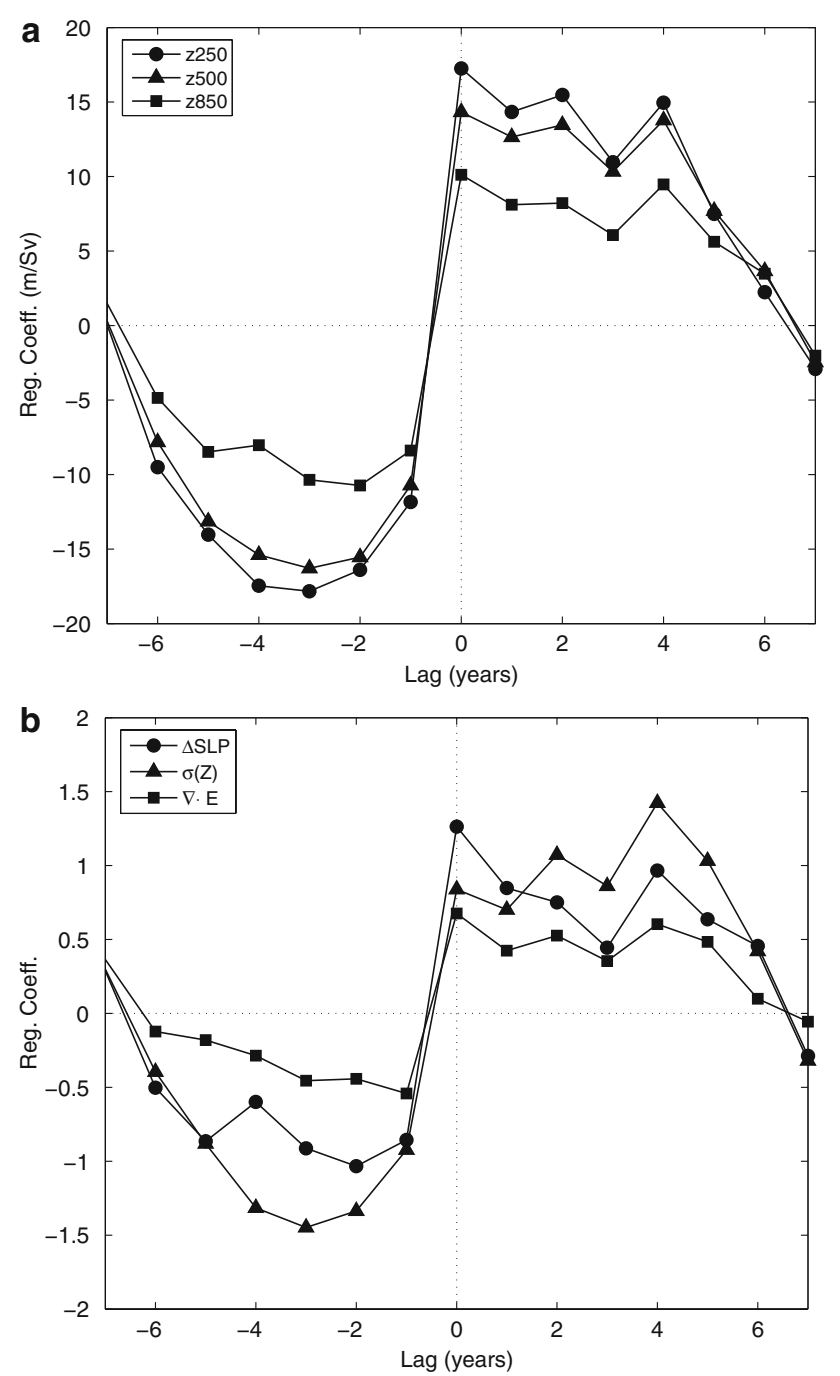

Fig. 16 Regression coefficients of winter fields with the MOC index averaged in the Atlantic region $\left(60^{\circ} \mathrm{W}-0^{\circ}\right)$ : a difference between $20^{\circ}-$ $60^{\circ} \mathrm{N}$ and $60^{\circ}-80^{\circ} \mathrm{N}$ averages in geopotential height regression coefficients at three different pressure levels $(250,500$, and $850 \mathrm{hPa})$; and $\mathbf{b} \triangle \mathrm{SLP}$ denotes difference in sea level pressure regression coefficients between $20^{\circ}-60^{\circ} \mathrm{N}$ and $60^{\circ}-80^{\circ} \mathrm{N}$ averages $(\mathrm{hPa} / \mathrm{Sv}), \sigma(Z)$ denotes regression coefficients of the band-pass (2.5 to 6 days) filtered standard deviation of geopotential height at $500 \mathrm{hPa}$ averaged over $40^{\circ}-80^{\circ} \mathrm{N}(\mathrm{m} / \mathrm{Sv})$, and $\nabla \cdot E$ denotes regression coefficients of the divergence of Hoskins' E-vector at $250 \mathrm{hPa}$ averaged over $40^{\circ}-80^{\circ} \mathrm{N}$ $\left(10^{-6} \mathrm{~m} \mathrm{~s}^{-2} / \mathrm{Sv}\right)$

such a solution increases if one considers possible climatic impacts of such a behavior. The regression analysis on the surface air temperature for the ST1 experiment shows that the maximum regression coefficient is about 2 and $3.2 \mathrm{~K} /$ $\mathrm{Sv}$ on the annual mean and winter, respectively, in the northern North Atlantic. The region of influence is mostly restricted to the vicinity of the northern North Atlantic, including the Labrador Sea, and Greenland. Since the maximum difference shown in the composite analysis is about $5 \mathrm{~Sv}$, the effect of the oscillation could be climatically important. On the other hand, the regression analysis of precipitation only shows a moderate sensitivity. The implication of the results is still limited by the lack of comparison with paleo-proxy records. Nonetheless, there may be a relevance to the glacial climate when the Norwegian Sea was seasonally ice covered, and winter sea ice margin was extended southward to $55^{\circ} \mathrm{N}$ during the LGM and to $40^{\circ} \mathrm{N}$ during extreme events (de Vernal et al. 2006). The existence of two metastable states in climate with extensive sea ice cover might be of importance for abrupt climate changes during the glacial period, even though the simulated global temperature change between CTRL and ST1 is only $2.5 \mathrm{~K}$.

It is worth to note that similar metastable states are also captured in this model during so-called water-hosing experiments (Stocker et al. 2007). In those experiments, perturbation freshwater fluxes with different peak strengths from 0.5 to $2 \mathrm{~Sv}$ are introduced in the northern North Atlantic between 50 and $70^{\circ} \mathrm{N}$ for 200 years, and the MOC dramatically weakens. During the recovery of the MOC after the perturbation of freshwater fluxes are ceased, the MOC time series exhibits a very similar oscillatory state as in the TR1, TR2, and ST1 experiments. The oscillatory behavior appears when the mean strength of MOC stays relatively constant at about 11-12 Sv for an extended period of time, consistent with the present study (Stocker et al. 2007). The analyses that only require monthly mean fields were repeated for those simulations, and the time scale of the oscillations and mechanisms are confirmed to be the same. These additional results confirm that the oscillatory behavior is not unique to partly accidental results in our experimental design, and that the oscillations can be excited by either thermal or freshwater perturbations. It also verifies that the use of the ocean acceleration during the spinup phase does not affect the existence of the oscillatory weak MOC mode (after the acceleration is turned off) because the acceleration was not used in the water hosing experiments at all.

The following mechanism is proposed for the simulated decadal MOC oscillations in a cold climate state (Fig. 17). The oscillations have a periodicity of about 13 years, and fundamentally arise from oceanic processes as discussed in Sect. 4.2 and indicated in the dashed box in Fig. 17a. We begin with positive salinity and density anomalies developed in the northern North Atlantic. This positive density anomaly is advected to the northeast towards the Irminger Sea, and induces anomalous cyclonic circulation in about 2 years. The anomalous cyclonic circulation, in turn, generates the negative salinity and density anomalies by advecting the fresher Labrador Sea near-surface water in the region of original positive salinity and density anomalies in about another 4 years. This loop completes onehalf the oscillation cycle, and the deep convection and 

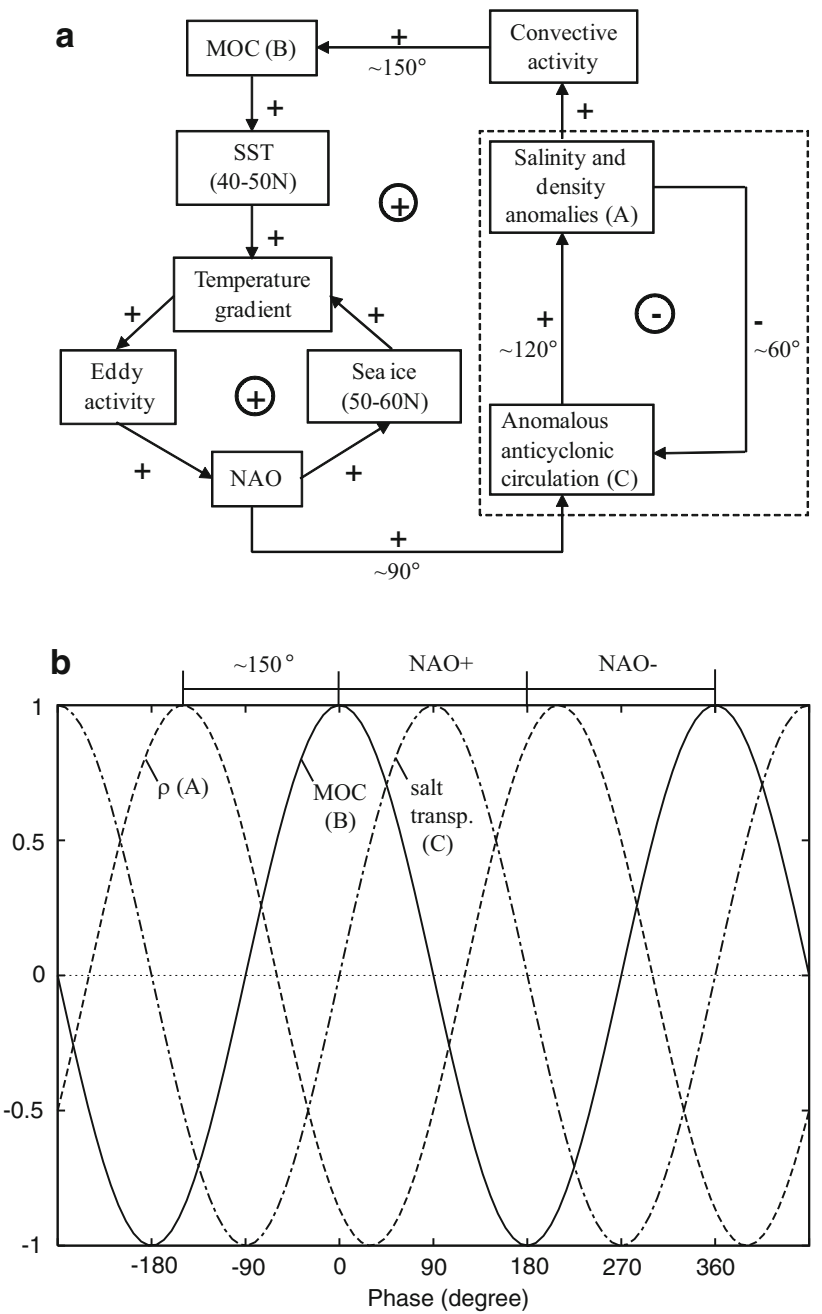

Fig. 17 Schematic diagram of physical mechanisms of the MOC oscillation cycles investigated in this study (see text for details): a The signs attached to the arrows indicate the correlation between changes in the two boxes. The resulting net feedbacks for a loop are represented by circled signs. Rough approximation for the elapsed phase of the cycle is also shown in degrees. One-half the oscillation cycle is indicated by a dashed rectangle; and $\mathbf{b}$ phase relations between $(A),(B)$, and $(C)$ in $\mathbf{a}$

MOC follows cycles of the near-surface density anomalies. The MOC lags behind the convection by about 5 years. When the MOC is in its strongest state, accompanied anomalous heat transport produces positive SST anomaly near the surface off the east coast of North America between 40 and $50^{\circ} \mathrm{N}$. This enhances the local meridional temperature gradient and baroclinicity in the atmosphere, which in turn enhances transient eddy activity. The enhanced transient eddy activity increases meridional convergence of zonal momentum fluxes near $60^{\circ} \mathrm{N}$, and leads to a positive phase of NAO. Since the positive NAO tends to increase the amount and extent of sea ice in the Labrador Sea and western subpolar North Atlantic, it results in a further increase of the meridional temperature gradient around $45-55^{\circ} \mathrm{N}$. This positive feedback loop occurs mostly in the atmosphere and operates relatively quickly but persists for several years. The persisting positive NAO derives anomalous anticyclonic circulation in the subpolar region in about 3 years, which advects less fresh Labrador Sea near-surface water, and generates the positive salinity and density anomalies in the northern North Atlantic in about another 4 years. The MOC-NAO interaction operates as a positive feedback, and the anomalous positive salt transport enhanced by NAO help reversing the negative density anomaly and vice versa as illustrated in Fig. 17b.

In this proposed mechanism, sea ice extent near and south of the Labrador Sea plays an important role by generating a large local thermal anomaly and changes in meridional temperature gradient around $45-55^{\circ} \mathrm{N}$. In addition, the oscillatory mode only appears when the GIN Sea is completely covered by sea ice in winter and the deep convection ceases there. In this state, the convection only occurs south of Greenland where the center of action of the oscillation is located. Variations in sea ice cover and capping of the deep convection area south of Greenland might also contribute to fluctuations of convection because heat cannot be efficiently damped to the atmosphere when the ocean surface is covered by ice (Figs. 4c, d, 11b).

Observations suggest that a basin-wide negative North Atlantic SST anomaly associated with the AMO is accompanied by the positive phase of the NAO (Grosfeld et al. 2007). The signs of the SST anomaly south of Greenland and the phase of the NAO are in line with our results. However, our results exhibit a negative SST anomaly south of Greenland with a positive MOC anomaly, in contrast to the AMO assuming that the AMO is induced by MOC variations. In addition, the SST anomaly in our decadal oscillations exhibits a tripole pattern (Fig. 15a, b), typical of the observed NAO (Visbeck et al. 2003), whereas the AMO exhibits a monopole SST anomaly. The tripole pattern perhaps suggests two-way interactions between the atmosphere and ocean in our decadal oscillations, and a dominance of oceanic forcing on the atmosphere in the AMO. It should be noted that the time scale of the two oscillations are different and also the background climate is substantially colder in our experiments with sea ice playing an important role.

For the same CCSM3 model under the present-day conditions, Danabasoglu (2008) found the MOC oscillations with periods of about 20-21 years for the two higher resolution settings (T42 and T85) while it is about 100-year periodicity for the coarse resolution setting (T31) of the model. The latter resolution is identical to the one used in the present study and the decadal oscillations are not found under the present-day conditions as in this study. It was concluded that their interdecadal oscillations occur as a 
result of interactions between convection in the Labrador Sea, MOC, NAO, and subpolar gyre circulations. As stated in the introduction, some sort of links between MOC and NAO variations have also been suggested in other studies (Delworth et al. 1993; Timmermann et al. 1998; Dong and Sutton 2005; Dai et al. 2005). All these models show that the near-maximum MOC anomaly is accompanied by the positive NAO phase, consistent with the present study. In Timmermann et al. (1998), the NAO influences the MOC via Ekman transport and surface freshwater fluxes, whereas anomalous subpolar gyre circulation appears as driver in Dong and Sutton (2005) which is also suggested here. Danabasoglu (2008) argues that temperature and salinity anomalies in the deepwater formation site are initiated by the NAO-induced changes in sea ice cover and vertical upwelling, both of which have a minor direct effect on these variables in the present study. In addition to how the NAO links to the MOC, whether the NAO is an essential ingredient in generating the oscillations or simply a passive player depends on the models, and requires further studies.

The current model has a large cold (max. bias: $\sim-10 \mathrm{~K}$ ) and fresh (max. bias: $\sim-5 \mathrm{psu}$ ) bias in SST and salinity, respectively, from the western to central North Atlantic around $40^{\circ} \mathrm{N}$. Note that this bias exists in all three CCSM3 versions with smaller extent and further north in higher resolution settings (Large and Danabasoglu 2006). This bias might be responsible for the double sinking regions seen in the meridional overturning stream function near $40-50^{\circ}$ and $60^{\circ} \mathrm{N}$ (Fig. 2 in Bryan et al. 2006). The fact that our oscillatory sinking anomalies primarily occur around $60^{\circ} \mathrm{N}$ provides some confidence that the bias near $40^{\circ} \mathrm{N}$ may not be critical. Nevertheless, it is possible that some of the responses such as the SST changes in the $40-50^{\circ} \mathrm{N}$ are somewhat exaggerated due to this bias. In addition, the mean strength of MOC becomes larger (Bryan et al. 2006, Table 1) and ocean heat transport increases as one goes to higher resolution settings (Yeager et al. 2006, Fig. 9). Therefore, the robustness of the existence of two quasistable solutions including the oscillatory solution found in this study needs to be revisited with future models.

The present study is restricted to only one model with one resolution setting, and this limitation should be stressed. In addition, no claim is made that the simulated decadal oscillations of the Atlantic MOC in a cold climate state had happened in the past. Rather, our intention is to reveal and share a new theoretically interesting solution found in a fully-coupled, non-flux adjusted state-of-the-art climate model. It is our hope to encourage comparisons on various stable solutions and physical mechanisms. This will increase our understanding of the model behavior in general and on feedback processes operating in each model system.
Acknowledgments We would like to thank NCAR for their continuous effort in developing, improving, and releasing the Community Climate System Model. The restart files kindly provided by NCAR saved an enormous amount of our computational time. We thank Steve Yeager in the NCAR Ocean Model Working Group for his technical help. Constructive comments by three anonymous reviewers are greatly appreciated. Developers of freely available softwares, SCRIP, NCL, and Ferret are also appreciated. This work is supported by the National Centre of Competence in Research (NCCR) Climate funded by the Swiss National Science Foundation and the EU project EPICA MIS. A substantial part of the computations was conducted on IBM Power 4 at the Swiss National Supercomputing Centre (CSCS) in Manno. Stefan Zoller and Kay Bieri maintained the local computing facility.

\section{References}

Aeberhardt M, Blatter M, Stocker TF (2000) Variability on the century time scale and regime changes in a stochastically forced zonally averaged ocean-atmosphere model. Geophys Res Lett 27(9):1303-1306

Ammann CM, Meehl GA, Washington WM, Zender CS (2003) A monthly and latitudinally varying volcanic forcing dataset in simulations of 20th century climate. Geophys Res Lett 30(12):L1657, doi:10.1029/2003GL016875

Blackmon ML (1976) A climatological spectral study of the $500 \mathrm{mb}$ geopotential height of the Northern Hemisphere. J Atmos Sci 33(8):1607-1623

Blunier T, Brook EJ (2001) Timing of millennial-scale climate change in Antarctica and Greenland during the last glacial period. Science 291(5501):109-112

Blunier T, Chappellaz J, Schwander J, Dällenbach A, Stauffer B, Stocker TF, Raynaud D, Jouzel J, Clausen HB, Hammer C, Johnsen SJ (1998) Asyncrony of Antarctic and Greenland climate change during the last glacial period. Nature 394:739_ 743

Blunier T, Chappellaz J, Schwander J, Stouffer B, Raynaud D (1995) Variations in atmospheric methane concentration during the Holocene epoch. Nature 374(6517):46-49

Bretherton CS, Widmann M, Dymnikov VP, Wallace JM, Bladé I (1999) The effective number of spatial degrees of freedom of a time-varying field. J Clim 12(7):1990-2009

Broecker WS (1998) Paleocean circulation during the last deglaciation: a bipolar seasaw? Paleoceanography 13(2):119-121

Bryan FO, Danabasoglu G, Nakashiki N, Yoshida Y, Kim DH, Tsutui J, Doney SC (2006) Response of the North Atlantic thermohaline circulation and ventilation to increasing carbon dioxide in CCSM3. J Clim 19(11):2382-2397

Bryan K (1984) Accelerating the convergence to equilibrium of ocean-climate models. J Phys Oceanogr 14(4):666-673

Bryan K, Hansen FC (1995) A stochastic model of North Atlantic climate variability on decade-to-century time scales. In: CR Committee (ed) Natural climate variability on decade-to-century time scales. National Research Council, Washington, pp 355364

Collins WD, Bitz CM, Blackmon ML, Bonan GB, Bretherton CS, Cargon JA, Chang P, Doney SC, Hack JJ, Henderson TB, Kiehl JT, Large WG, McKenna DS, Snater BD, Smith RD (2006a) The community climate system model version 3 (CCSM3). J Clim 19(11):2122-2143

Collins WD, Rasch PJ, Boville BA, Hack JJ, McCaa JR, Williamson DL, Briegleb BP, Bitz CM, Lin SJ, Zhang M (2006b) The formulation and atmospheric simulation of the community atmosphere model version 3 (CAM3). J Clim 19(11):2144-2161 
Crowley TJ (2000) Causes of climate change over the past 1000 years. Science 289(5477):270-277

Cunningham SA, Kanzow T, Rayner D, Baringer MO, Johns WE, Marotzke J, Longworth HR, Grant EM, Hirschi JJM, Beal LM, Meinen CS, Bryden HL (2007) Temporal variability of the Atlantic meridional overturning circulation at $26.5^{\circ} \mathrm{N}$. Science 317(5840):935-938

Dai A, Hu A, Meehl GA, Washington WM, Strand WG (2005) Atlantic thermohaline circulation in a coupled general circulation model: unforced variations versus forced changes. J Clim 18(16):3270-3293

Danabasoglu G (2008) On multidecadal variability of the Atlantic meridional overturning circulation in the Community Climate System Model version 3. J Clim 21(21):5524-5544

de Vernal A, Rosell-Melé A, Kucera M, Hillaire-Marcel C, Eynaud F, Weinelt M, Dokken T, Kageyama M (2006) Comparing proxies for the reconstruction of LGM sea-surface conditions in the northern North Atlantic. Quat Sci Rev 25(21-22):2820-2834

Delworth T, Manabe S, Stouffer J (1993) Interdecadal variations of the thermohaline circulation in a coupled ocean-atmosphere model. J Clim 6(11):1993-2011

Delworth TL, Greatbatch RJ (2000) Multidecadal thermohaline circulation variability driven by atmospheric surface flux forcing. J Clim 13(9):1481-1495

Delworth TL, Stouffer RJ, Dixon KW, Spelman MJ, Knutson TR, Broccoli AJ, Kushner PJ, Wetherald RT (2002) Review of simulations of climate variability and change with the GFDL R30 coupled climate model. Clim Dyn 19(7):555-574

Deser C, Magnusdottir G, Saravanan R, Phillips A (2004) The effects of North Atlantic SST and sea ice anomalies on the winter circulation in CCM3. part II: direct and indirect components of the response. J Clim 17(5):877-889

Dong B, Sutton RT (2005) Mechanism of interdecadal thermohaline circulation variability in a coupled ocean-atmosphere GCM. J Clim 18(8):1117-1135

Etheridge DM, Steele LP, Langenfelds RL, Francey RJ, Barnola JM, Morgan VI (1996) Natural and anthropogenic changes in atmospheric $\mathrm{CO}_{2}$ over the last 1000 years from air in Antarctic ice and firn. J Geophys Res 101(D2):4115-4128

Flückiger J, Dällenbach A, Blunier T, Stauffer B, Stocker TF, Raynaud D, Barnola JM (1999) Variations in atmospheric $\mathrm{N}_{2} \mathrm{O}$ concentration during abrupt climatic changes. Science 285(5425):227-230

Flückiger J, Monnin E, Stauffer B, Schwander J, Stocker TF, Chappellaz J, Raynaud D, Barnola JM (2002) High-resolution Holocene $\mathrm{N}_{2} \mathrm{O}$ ice core record and its relationship with $\mathrm{CH}_{4}$ and $\mathrm{CO}_{2}$. Global Biogeochem Cycles 16(1):L1010, doi:10.1029/ 2001GB001417

Ganachaud A (2003) Large-scale mass transports, water mass formation, and diffusivities estimated from World Ocean Circulation Experiment (WOCE) hydrographic data. J Geophys Res 108(C7):3213, doi:10.1029/2002JC001565

Ganachaud A, Wunsch C (2000) Improved estimates of global ocean circulation, heat transport and mixing from hydrographic data. Nature 408:453-457

Gent PR, McWilliams JC (1990) Isopycnal mixing in ocean circulation models. J Phys Oceanogr 20(1):150-155

González-Rouco JF, Beltrami H, Zorita E, von Storch H (2006) Simulation and inversion of borehole temperature profiles in surrogate climates: spatial distribution and surface coupling. Geophys Res Lett 33:L01703, doi:10.1029/2005GL024693

Greatbatch RJ, Zhang S (1995) An interdecadal oscillation in an idealized ocean basin forced by constant heat flux. J Clim 8(1):81-91

Griffies SM, Tziperman E (1995) A linear thermohaline oscillator driven by stochastic atmospheric forcing. J Clim 8(10):2440 2453
Grosfeld K, Lohmann G, Rimbu N, Fraedrich K, Linkeit F (2007) Atmospheric multidicadal variations in the North Atlantic realm: Proxy data, observations, and atmospheric circulation model studies. Clim Past 3:39-50

Holland MM, Bitz CM, Eby M, Weaver AJ (2001) The role of iceocean interactions in the variability of the North Atlantic thermohaline circulation. J Clim 14(5):656-675

Hoskins BJ, James IN, White GH (1983) The shape, propagation and mean-flow interaction of large-scale weather systems. J Atmos Sci 40(7):1595-1612

Hughes TMC, Weaver AJ (1994) Multiple equilibria of an asymmetric two-basin ocean model. J Phys Oceanogr 24(3):619-637

Hurrell JW, Visbeck M, Busalacchi A, Clarke RA, Delworth TL, Dickson RR, Johns WE, Koltermann KP, Kushnir Y, Marshall D, Mauritzen C, McCartney MS, Piola A, Reason C, Reverdin G, Schott F, Sutton R, Wainer I, Wright D (2006) Atlantic climate variability and predictability: a CLIVAR perspective. J Clim 19:5100-5121

IPCC (2001) Climate change 2001: the scientific basis. In: Houghton JT, Ding Y, Griggs DJ, Noguer M, van der Linden PJ, Dai X, Maskell K, Johnson CA (eds) Contribution of working group I to the third assessment report of the intergovenmental panel on climate change. Cambridge University Press, Cambridge, $881 \mathrm{pp}$

IPCC (2007) Climate change 2007: the physical science basis. In: Solomon S, Qin D, Manning M, Chen Z, Marquis M, Averyt KB, Tignor M, Miller HL (eds) Contribution of working group I to the fourth assessment report of the intergovenmental panel on climate change. Cambridge University Press, Cambridge, 996 pp

Jungclaus JH, Haak H, Latif M, Mikolajewicz U (2005) Arctic-North Atlantic interactions and multidecadal variability of the meridional overturning circulation. J Clim 18(19):4013-4031

Knutti R, Flückiger J, Stocker TF, Timmermann A (2004) Strong hemispheric coupling of glacial climate through freshwater discharge and ocean circulation. Nature 430:851-856

Kushnir Y, Robinson WA, Bladé I, Hall NMJ, Peng S, Sutton R (2002) Atmospheric GCM response to extratropical SST anomalies: synthesis and evaluation. J Clim 15(16):2233-2256

Large WG, Danabasoglu G (2006) Attribution and impacts of upperocean biases in CCSM3. J Clim 19(11):2325-2346

Large WG, McWilliams JC, Doney SC (1994) Oceanic vertical mixing: a review and a model with a nonlocal boundary layer parameterization. Rev Geophys 32(4):363-403

Lean J, Beer J, Bradley R (1995) Reconstruction of solar irradiance since 1610: Implications for climate change. Geophys Res Lett 22(23):3195-1398

Luksch U, Raible CC, Blender R, Fraedrich K (2005) Decadal cyclone variability in the North Atlantic. Meteorol Z 14(6):747-753

Lumpkin R, Speer K (2003) Large-scale vertical and horizontal circulation in the North Atlantic ocean. J Phys Oceanogr 33(9):1902-1920

Magnusdottir G, Deser C, Saravanan R (2004) The effects of North Atlantic SST and sea ice anomalies on the winter circulation in CCM3. part I: main features and storm track characteristics of the response. J Clim 17(5):857-876

Manabe S, Stouffer RJ (1988) Two stable equilibria of a coupled ocean-atmosphere model. J Clim 1(9):841-866

Mann ME, Zhang Z, Hughes MK, Bradley RS, Miller SK, Rutherford S, Ni F (2008) Proxy-based reconstructions of hemispheric and global surface temperature variations over the past two millennia. Proc Natl Acad Sci USA 105(36):13252-13257

Mikolajewicz U, Maier-Reimer E (1994) Mixed boundary conditions in ocean general circulation models and their influence on the stability of the model's conveyor belt. J Geophys Res 99(C11):22633-22644

Oleson KW, Dai Y, Bonan G, Rosilovich M, Dickinson R, Dirmeyer P, Hoffman F, Houser P, Levis S, Niu GY, Thornton P, 
Vertenstein M, Yang ZL, Zeng X (2004) Technical description of the community land model (CLM). NCAR Technical Note, NCAR/TN-461+STR, $173 \mathrm{pp}$

Otto-Bliesner BL, Tomas R, Brady EC, Ammann C, Kothavala Z, Clauzet G (2006) Climate sensitivity of moderate- and lowresolution versions of CCSM3 to preindustrial forcings. J Clim 19(11):2567-2583

Peng S, Whitaker JS (1999) Mechanisms determining the atmospheric response to midlatitude SST anomalies. J Clim 12(5):1393-1408

Press WH, Teukolsky SA, Vetterling WT, Flannery BP (1992) Numerical recipes in FORTRAN: the art of scientific computing, 2nd edn, Cambridge University Press, New York, 963 pp

Rahmstorf S (1996) Comments on "Instability of the thermohaline circulation with respect to mixed boundary conditions: is it really a problem for realistic models?" J Phys Oceanogr 26(6):1099-1105

Rahmstorf S, Willebrand J (1995) The role of temperature feedback in stabilizing the thermohaline circulation. J Phys Oceanogr 25(5):787-805

Rind D, Shindell D, Perlwitz J, Lerner J, Lonergan P, Lean J, McLinden C (2004) The relative importance of solar and anthropogenic forcing of climate change between the Maunder Minimum and the present. J Clim 17(5):906-929

Smethie WM Jr, Fine RA (2001) Rates of North Atlantic deep water formation calculated from chlorofluorocarbon inventories. Deep Sea Res Part I 48(1):189-215

Stocker TF (1998) The seesaw effect. Science 282(5386):61-62

Stocker TF (2000) Past and future reorganizations in the climate system. Quat Sci Rev 19(1-5):301-319

Stocker TF, Johnsen SJ (2003) A minimum thermodynamic model for the bipolar seesaw. Paleoceanography 18(4):1087, doi: 10.1029/2003PA000920

Stocker TF, Timmermann A, Renold M, Timm O (2007) Effects of salt compensation on the climate model response in simulations of large changes of the Atlantic meridional overturning circulation. J Clim 20(24):5912-5928

Stouffer RJ, Yin J, Gregory JM, Dixon KW, Spelman MJ, Hurlin W, Weaver AJ, Eby M, Flato GM, Hasumi H, Hu A, Jungclaus JH, Kamenkovich IV, Levermann A, Montoya M, Murakami S, Nawrath S, Oka A, Peltier WR, Robitaille DY, Sokolov A, Vettoretti G, Weber SL (2006) Investigating the causes of the response of the thermohaline circulation to past and future climate changes. J Clim 19(8):1365-1387

Talley LD, Raid JL, Robbins PE (2003) Data-based meridional overturning streamfunctions for the global ocean. J Clim 16(19):3213-3226

Thorpe RB, Gregory JM, Johns TC, Wood RA, Mitchell JFB (2001) Mechanisms determining the Atlantic thermohaline circulation response to greenhouse gas forcing in a non-flux-adjusted coupled climate model. J Clim 14(14):3102-3116

Timmermann A, Latif M, Voss R, Grötzner A (1998) Northern Hemisphere interdecadal variability: a coupled air-sea mode. J Clim 11(8):1906-1931

Toggweiler JR, Tziperman E, Feliks Y, Bryan K, Griffies SM, Samuels B (1996) Reply. J Phys Oceanogr 26(6):1106-1110

Torrence C, Compo GP (1998) A practical guide to wavelet analysis. Bull Am Meteor Soc 79(1):61-78

Tziperman E, Toggweiler JR, Bryan K, Feliks Y (1994) Instability of the thermohaline circulation with respect to mixed boundary conditions: is it really a problem for realistic models? J Phys Oceanogr 24(2):217-232
Vellinga M, Wood RA (2002) Global climatic impacts of a collapse of the Atlantic thermohaline circulation. Clim Chan 54(3):251267

Vellinga M, Wu P (2004) Low-latitude freshwater influence on centennial variability of the Atlantic thermohaline circulation. J Clim 17(23):4498-4511

Visbeck M, Chassignet E, Curry R, Delworth T, Dickson B, Krahmann G (2003) The Ocean's response to North Atlantic Oscillation variability, Geophysical monograph series, chap 6, vol 134. American Geophysical Union, Washington, pp 113-146

von Storch H, Zwiers FW (1999) Statistical analysis in climate research. Cambridge University Press, Cambridge, $484 \mathrm{pp}$

Walter K, Luksch U, Fraedrich K (2001) A response climatology of idealized midlatitude thermal forcing experiments with and without a storm track. J Clim 14(4):467-484

Weaver AJ, Hughes TMC (1994) Rapid interglacial climate fluctuations driven by North Atlantic ocean circulation. Nature 367:447-450

Weaver AJ, Marotzke J, Cummins PF, Sarachik ES (1993) Stability and variability of the thermohaline circulation. J Phys Oceanogr 23(1):39-60

Weaver AJ, Sarachik ES (1991a) Evidence for decadal variability in an ocean general circulation model: an advective mechanism. Atmos Ocean 29:197-231 (RW Stewart symposium special edition)

Weaver AJ, Sarachik ES (1991b) The role of mixed boundary conditions in numerical models of the ocean's climate. J Phys Oceanogr 21(9):1470-1493

Weaver AJ, Sarachik ES, Marotzke J (1991) Freshwater flux forcing of decadal and interdecadal oceanic variability. Nature 353(6347):836-838

Weisse R, Mikolajewicz U, Maier-Reimer E (1994) Decadal variability of the North Atlantic in an ocean general circulation model. J Geophys Res 99(C6):12411-12421

Wilks DS (1995) Statistical methods in the atmospheric sciences. In: International geophysics series, vol 59. Acdemic Press, San Diego, $467 \mathrm{pp}$

Yang J, Neelin JD (1993) Sea-ice interactions with the thermohaline circulation. Geophys Res Lett 20(2):217-220

Yang JY, Neelin JD (1997) Decadal variability in coupled sea-icethermohaline circulation systems. J Clim 10(12):3059-3076

Yeager SG, Shields CA, Large WG, Hack JJ (2006) The lowresolution CCSM3. J Clim 19(11):2545-2566

Yoshimori M, Raible CC, Stocker TF, Renold M (2006) On the interpretation of low-latitude hydrological proxy records based on Maunder Minimum AOGCM simulations. Clim Dyn 27(5):493-513

Yoshimori M, Stocker TF, Raible CC, Renold M (2005) Externally forced and internal variability in ensemble climate simulations of the Maunder Minimum. J Clim 18(20):4253-4270

Zhang R, Delworth TL (2005) Simulated tropical response to a substantial weakening of the Atlantic thermohaline circulation. J Clim 18(12):1853-1860

Zhang S, Greatbatch RJ, Lin CA (1993) A reexamination of the polar halocline catastrophe and implications for coupled oceanatmosphere modeling. J Phys Oceanogr 23(2):287-299

Zhang S, Lin CA, Greatbatch RJ (1995) A decadal oscillation due to the coupling between an ocean circulation model and a thermodynamic sea-ice model. J Mar Res 53(1):79-106 